\title{
A Red Flag for Hong Kong Credit Ratings
}

\author{
AIIFL Working Paper No. 18
}

\author{
July 2016
}

Asian Institute of International Financial Law

Faculty of Law

The University of Hong Kong

www.AIIFL.com

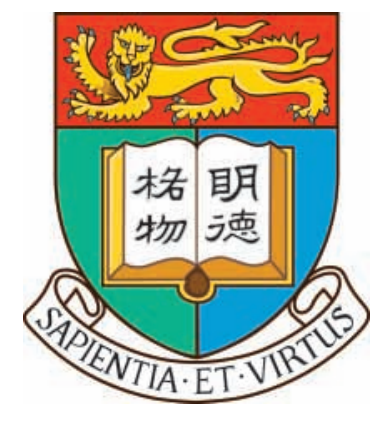

(C) July 2016 the author. All rights reserved. Short text extracts may be quoted without explicit permission provided that full credit including the "C)" notice is given to the source. 


\title{
A Red Flag for Hong Kong Credit Ratings
}

\author{
Syren Johnstone*
}

\begin{abstract}
$^{* *}$
In July 2011 Moody's Investors Service Hong Kong issued a report that used a system of red flags to highlight corporate governance and accounting risks in a specified population of listed companies. Although Moody's did not consider the report a credit rating, the Securities and Futures Commission, and the Securities and Futures Appeals Tribunal in its March 2016 determination, regarded the issuance of it as part of Moody's regulated activity as a provider of credit rating services. As such, Moody's was held subject to regulatory codes of conduct it was said to have breached, and was consequently disciplined. Moody's has since appealed that determination, which will bring the case before the Court of Appeal.
\end{abstract}

This paper undertakes a detailed legal analysis of the Tribunal's determination. It suggests the Tribunal's purposive approach to legislative interpretation is flawed, and its determination impaired by the way the Tribunal has framed the syntax of its reasoning and has conflated important distinctions between credit risk, creditworthiness, credit ratings and the methodology used to produce a rating opinion. Other legislative provisions relevant to the publication of information are reviewed and it is noted there is no lacuna in Hong Kong's law that would necessitate the approach taken by the Tribunal to address the perceived wrongdoing. Whether the Tribunal's interpretation of the law is necessary or consistent with the policy intent of the Legislature is queried.

The ramifications of a Court of law upholding the Tribunal's determination are considered. Locally this includes blurring the perimeter around regulated and unregulated activities and the possible creation of an uneven playing field. Of particular significance for Hong Kong's credit rating industry, it may create uncertainties as to whether Hong Kong would remain an equivalent jurisdiction for the purposes of recognition under European Union regulations. The paper concludes with a brief consideration of the regulatory approach to managing the introduction of a new regulatory regime.

\footnotetext{
* Adjunct Associate Professor, Faculty of Law, University of Hong Kong; Fellow, Asian Institute of International Financial Law; Solicitor (England \& Wales and Hong Kong, nonpractising); Director, Keel Consulting

* This paper is supported by the RGC Theme-based Research Scheme Project: "Enhancing Hong Kong's Future as a Leading International Financial Centre". The author would like to thank for their comments and assistance Professor Douglas Arner, Paul Lejot, Nigel Davis, Kingsley Ong and Evan Gibson (all of University of Hong Kong), and Antonio Da Roza (Barrister); the views expressed and any errors remain those of the author.
} 


\section{Contents}

$\begin{array}{ll}\text { Abstract } & 01\end{array}$

$\begin{array}{ll}\text { Executive summary } & 03\end{array}$

1. Introduction 08

1.1 The regulatory oversight of credit rating agencies

1.2 The position in Hong Kong

1.3 The Moody's case in Hong Kong

1.4 Structure of this paper

2. The Hong Kong case

2.1 The RF Report

2.2 The regulatory context

2.3 The SFC's position

2.4 The Tribunal's determination

3. The Tribunal's approach

3.1 Entry point for application of the purposive approach

3.2 Consideration of extrinsic factors

3.2.1 Issuer's intent

3.2.2 Consequences in the market

3.2.3 The press release

3.2.4 Conclusion

3.3 Regulated and non-regulated services

3.4 Conclusions on the Tribunal's purposive approach

4. Construing the RF Report as a credit rating

4.1 The Tribunal's position

4.2 Ratings and creditworthiness distinguished

4.3 Construing 'credit rating'

4.3.1 Meaning of 'using a defined ranking system'

4.3.2 Meaning of 'primarily regarding'

4.4 Conclusions on the construal of "credit rating"

5. Construing the RF Report as part and parcel of Moody's other credit ratings

5.1 "Supplemental to"

5.1.1 The subject is methodology

5.1.2 Negative reading

5.1.3 Transformational reading

5.2 An alternative interpretation

6. Meeting policy objectives

6.1 Ramifications of the determination

6.1.1 Local implications

6.1.2 International context

6.2 Other provisions of the SFO are relevant

7. Conclusions on credit rating

8. The regulatory approach 


\section{Executive summary}

The regulatory oversight of credit rating agencies ("CRAs") introduced in Hong Kong in June 2011 has recently been the subject of a determination made by the Securities and Futures Appeals Tribunal (the "Tribunal") that is now on its way to an appeal before the Hong Kong Court of Appeal. The case concerns whether the issue of a report by Moody's Investors Service Hong Kong Limited ("Moody's") constituted a credit rating and the provision of credit rating services, matters governed by the Securities and Futures Ordinance ("SFO"). The Tribunal determined that it did, rendering the issue of Moody's report subject to the requirements of non-statutory regulations issued by the Securities and Futures Commission ("SFC").

The case is of particular interest for a number of reasons. It represents the first time since the development of an international approach to CRA regulatory oversight that the precise scope of a credit rating regulatory regime falls to be determined. Specifically, whether or not publishing an item of information constitutes credit rating activity for regulatory purposes. As such, it also represents an exploration of what reports issued by a CRA should be regarded as falling within the perimeter of its regulated activities. Locally, it represents the first time a substantive determination of the Tribunal has been appealed since its establishment under the SFO in 2003.

This paper analyzes the determination made by the Tribunal and the potential implications locally and internationally should the Court of Appeal uphold its determination.

The introduction of a CRA regulatory regime in Hong Kong is a result of international considerations, as discussed in Section 1 of this paper. The international community began to focus on the role of CRAs from around 2003 when work undertaken by the Financial Stability Board and the International Organization of Securities Commissions ("IOSCO") led to IOSCO's report, and subsequent statement of principles, on CRA activities. This was followed by a consensus post the 2008 global financial crisis that CRAs should be brought under regulatory oversight with various countries in turn implementing CRA regimes. Hong Kong modeled its regime on the principles and code issued by IOSCO, and with a view to ensuring ratings issued by CRAs based in Hong Kong would be serviceable in the EU in accordance with EU regulations.

Moody's report was issued less than six weeks after the CRA regime commenced in Hong Kong. It comprised a framework in which red flags were assigned to specified Mainland China companies across a range of corporate governance and accounting risk issues. Based on the effects of the report in the market, it appeared to be of considerable interest to both equity and debt investors. The prevailing environment of concern of regulators and investors over governance and accounting standards in Mainland companies, the targeted nature of the report, the cautionary note of its red flags, and Moody's status in the market, together contributed to this.

Although Moody's is licensed to engage in the provision of credit rating services (Type 10 regulated activity), it did not itself consider the report to be a credit rating or part of its Type 10 activities. The SFC, and subsequently the Tribunal, took a different view, namely, that the issuance of the report did fall within the SFC's regulatory oversight of Moody's activities qua its Type 10 licensed activities. As such, that brings the report and Moody's issuance of it within the jurisdiction of the SFC and renders it subject to SFC codes of conduct. The SFC alleged the report was defective in view of certain code requirements. The 
sanctions applied by the SFC and disputed by Moody's arise from alleged breaches of those non-statutory regulatory codes, not the law. However, the question of whether or not Moody's issuance of the report is subject to the jurisdiction of the SFC is a matter of statutory law, not the non-statutory regulations. Section 2 discusses Moody's report and introduces the Tribunal's determination.

The SFO provides the statutory basis of the CRA regime. Its definition of Type 10 regulated activity requires the preparation of "credit ratings", a term defined by the SFO. One starting point for assessing whether the issuance of the report constituted the provision of a credit rating would therefore be to examine the meaning of "credit rating" and apply it to the report. The analysis undertaken in Section 4 of this paper suggests the report does not satisfy the basic requirements of the statutory language to be a credit rating: (1) the report does discuss matters pertaining to credit risk but does not appear to be primarily concerned with creditworthiness; (2) the red flag framework can be regarded as a defined ranking system but lacks both the ordinality normally required of credit ratings and the ability to be used to meaningfully signify creditworthiness; (3) the language of the report on a plain reading appears to eschew a connection between the red flag framework and creditworthiness; and (4) the factors examined by the report may share commonalities with factors relevant to methodologies used by CRAs but no opinion on creditworthiness appears to have been expressed. Taken together, the foregoing does not point to a credit rating that is a defective one - it points to a report that is not a credit rating.

The Tribunal did not assume the above starting point. It undertook a purposive interpretation of the law with a view to giving effect to the intention of the Legislature. That approach took as its focus the regulated activity of providing credit rating services. The analysis undertaken in Section 3 of this paper suggests the Tribunal's purposive approach may be flawed insofar as it does not adequately take into account the wider context and purpose of introducing CRA regulation in Hong Kong, nor other relevant provisions of the legislation. An important component of the Tribunal's approach was to look outside the four sides of the report, namely, Moody's intent in issuing the report, the reaction of the market to the report, and a press release issued the same day as the report. However, the CRA legislation makes no provision to consider such extrinsic matters, which notably stands in contrast to other provisions of the SFO that seek to attain similar objectives such as the quality of information in a market place and a clear delineation of regulated and unregulated activities. Following the established approach taken by the Court of Final Appeal, most recently in Pacific Sun Advisors Ltd and Another v. Securities and Futures Commission [2015] HKCFA 27, this discrepancy may indicate the Legislature did not intend extrinsic factors to be taken into account when determining the scope of the CRA regime where they have wished this to be the case they have expressed it in the legislation. Considering extrinsic matters therefore may be outside the remit of what appears to have been intended by the Legislature.

The Tribunal's purposive approach also encompasses the SFC's statutory powers to impose disciplinary action on regulated intermediaries. The analysis in Section 3.3 suggests the Tribunal's approach is based on a broad and unclearly justified interpretation of the reach of those powers. By default, it extends the regulatory jurisdiction of the SFC to an uncertain category of acts "related to" regulated activities. However, it is notable that the SFC's codes, made for the purpose of giving guidance as to the carrying on of regulated activities, do not appear to carry such a wide remit that they address activities that are not themselves regulated - there would be no legislative basis for the codes to do so. The Tribunal's broad approach to the exercise of statutory powers creates a number 
of problems including the potential creation of an uneven playing field between regulated and unregulated persons engaging in the same act. It is unclear whether the Tribunal's interpretation of the law furthers or in fact hinders the legislative purpose.

Putting aside the foregoing considerations, an assessment of the import attributed by the Tribunal to the press release issued by Moody's the same day as the report is considered in Section 5 of this paper. The Tribunal suggests that the press release, and its reference to the report being "supplemental to Moody's methodological approach to rating", is part of the means by which the report is conceived as amplifying, and becomes part of, Moody's credit ratings. However, the Tribunal's reading of these words in the press release appears stretched if not wholly unwarranted. For example, that the press release statement refers to Moody's methodological approach not, as the Tribunal has read it, to its ratings per se reflects a confused appreciation of the distinctions and relationships between methodology, the ranking system used, and the opinion expressed. As such, the Tribunal does not recognize, as the Court did in Bathurst Regional Council v Local Government Financial Services Pty Ltd (No 5) [2012] FCA 1200, that a rating once given is not dependent on a CRA's subsequent explanation of how it reached the rating. The understanding in Bathurst is consistent with the SFC's code of conduct, which requires an explanatory press release to be issued when a credit rating is issued or revised but which also implicitly recognizes that ratings and explanations of them remain distinct items attending different purposes. Moreover, the Tribunal's treatment of the press release is at odds with a more straightforward understanding of the press release (and to some extent the report itself) consistent with a commercial entity that wishes to highlight matters of potential interest to its primary client base.

The link between the report and credit rating services asserted by the Tribunal is tenuous at best, and appears based on an analysis that is in some ways back-tofront. It is noteworthy that the Tribunal did not undertake a detailed account of the specific language used by Hong Kong's Legislature when defining the term "credit rating" but merely regarded the term as broadly defined. While the Tribunal correctly notes the definition of "credit rating" is not concerned with the specific accountancy directives or mathematical formulae involved in producing a rating, its subsequent approach appears to conflate important distinctions and relationships between methodology and a rating opinion, and between elements of credit risk, creditworthiness and a credit rating. The approach taken in Hong Kong's legislation is consistent with the International Organization of Securities Commissions' definition of a credit rating as an assessment regarding creditworthiness that is expressed using a defined and established ranking system. However, this cannot be reversed into an understanding that credit ratings are assessments of credit risk that produce a defined ranking system.

There is obviously an enormous volume of published materials discussing the shortcomings of corporates that may be relevant to assessments of creditworthiness but which are not considered to be discussions of risk of default. They are instead characterized as, for example, research reports, business analyses, or perhaps discussions of corporate sustainability. Default may be a potential consequence of bad risk governance, but a discussion of bad risk governance, even if based around a ranking system, does not necessarily amount to an assessment of the risk of default. The SFC itself uses indicators such as loss making companies, frequent corporate restructuring and changes of auditors to assess corporate risk and to identify red flags. Such regulatory concerns are confluent with the interests of investors generally in the same way that welltargeted research discussing governance and accounting risks can help to reduce 
information asymmetries in the market without being rendered a discussion primarily regarding creditworthiness.

The analysis undertaken in this paper suggests the scope of "credit rating" and "providing credit rating services" is in fact subject to well-defined parameters in the SFO in which certain matters are to be considered to the exclusion of other considerations. These considerations raise significant doubts over the correctness of the Tribunal's determination. It is suggested that the Tribunal has, in effect, adopted the wrong starting point for its analysis. It is not consistent with either development of the CRA regulatory regime or the architecture of the SFO to frame an investigation into whether or not a credit rating has been issued by looking to the issuer's licensed status to determine the nature of a report it issues. Nor is it appropriate to selectively look at acts and consequences from a remedial point of view without considering other remedial provisions of the SFO that are arguably more clearly relevant to the alleged wrongdoing.

Although the Tribunal's determination is incapable of affecting the law it is nevertheless highly influential as to how the SFC goes about executing its regulatory function as well as the undertakings of regulated persons. However, when the Court of Appeal rules on Moody's appeal, law is established. Section 6 of this paper considers the implications of the Tribunal's determination should it be upheld in the Court of Appeal, in particular, whether it may be counterproductive to the policy intent of the Legislature. It is suggested that important purposes of the legislation and the introduction of CRA regulation in Hong Kong may be called into question. Locally, this includes (1) greater uncertainty as to what constitutes the regulated activity of providing credit rating services, (2) what reports of a CRA are to be regarded as subject to the SFC's regulatory oversight, (3) the creation of an uneven playing field for regulated as compared to unregulated persons, and (4) the potential impact on information asymmetry in the market as a consequence of widening a CRA's liability.

Internationally, and of particular significance for Hong Kong's credit rating industry, it may create uncertainties as to whether Hong Kong would remain an equivalent jurisdiction for the purposes of recognition under EU regulations, which is essential for ratings issued by Hong Kong licensed CRAs to be serviceable in the EU. As the SFC's case against Moody's is fundamentally based on the quality of information in the report, other relevant sections of the SFO that are concerned with information are reviewed and it is noted there is no lacuna in Hong Kong's legislation in this regard that would necessitate the approach taken by the Tribunal to address the perceived wrongdoing.

Any analysis of information connected to the CRA industry must be astute to important differences between elements of credit risk, the concept of creditworthiness, and the opinion that might be expressed on creditworthiness. Although the application of methodology gives rise to the formation of a rating opinion, it is divorced from the opinion once the opinion is expressed. It is also well accepted that not all information issued by CRAs constitute credit ratings. Conflating these distinctions leads to a muddled understanding of the CRA's undertaking, a confused approach to the statutorily defined term "credit rating", and consequential errors of analysis.

Given that (1) the definitions of "credit rating" and Type 10 regulated activity are clearly expressed and as such appear to serve their regulatory purposes, (2) other provisions of the SFO adequately address the problem of misleading information entering the market, and (3) the potential problems attendant on the Tribunal's approach, there does not appear to be any good reason to broaden the scope of the credit rating regime in the way undertaken by the Tribunal. 
Accordingly, the primary conclusion, discussed in Section 7 of this paper, is that the issue of the report and the red flag framework in it should not be regarded as constituting Type 10 regulated activity or a credit rating as such terms are defined by the law.

Taking a broader perspective on the Moody's case, it is noteworthy that at the time Moody's issued the report the CRA regulatory regime was only 41 days old, subject to some uncertainties as to how the SFC's general code of conduct would apply to CRAs in certain regards, and that the topic of the global financial crisis of 2008 and the role of CRAs in it was still a recent and sensitive issue. The SFC's approach to the report, electing to pursue Moody's publicly under the CRA regime, is in some ways puzzling when one considers (1) the newness of the CRA regime, (2) that it required treating the issuance of the report as being clearly part of Moody's credit rating services and not merely a research report falling under a CRA's other business analysis activities, (3) that no breaches were alleged of the SFC's code that specifically deals with CRA activities (the Code of Conduct for Persons Providing Credit Rating Services) and (4) the alternative approaches available to the SFC (assuming for this purpose the SFC's perception of the report). As noted in Section 8 of this paper, the SFC have a range of tools at their disposal for dealing with a perceived shortfall in standards, particularly where that involves information going into the market that it considers to be misleading. This may range from exercising its regulatory power to discipline, such as by way of private sanction, to bringing an action under the market misconduct provisions of the SFO.

Effective regulation frequently comprises an element of seeking the right balance and making assessments as to the gravity of a perceived wrongdoing. Moody's report was not free from errors and uncertainties. Nevertheless, putting aside the analysis presented in this paper, one can ask whether there was an alternative case for a more nuanced approach to managing the introduction of a new regulatory regime and effectively bringing an existing and well-established industry within the SFC's oversight. Or, to put it another way, what is the best way of developing a strategic partnership between regulator and a population of regulatees that serves to foster market standards? 


\section{INTRODUCTION}

\subsection{The regulatory oversight of credit rating agencies}

Credit rating agencies ("CRAs") have largely operated in an unregulated environment since their development out of mercantile credit agencies in the mid nineteenth century. ${ }^{1}$ While credit ratings first became recognized for regulatory purposes in the 1930s in the United States ("U.S."), CRAs were not themselves subject to regulatory oversight until 1975 when the United States Securities and Exchange Commission ("SEC") introduced the nationally recognized statistical rating organization ("NRSRO") designation, although the extent of the regulatory oversight was limited in scope and specific in purpose. ${ }^{2}$

In the early 2000's, prompted by high profile corporate collapses, the international community began to look more closely at the role of CRAs in the financial marketplace, and consequently whether they should be subject to regulatory oversight. Work undertaken by the Financial Stability Board ("FSB") and the International Organization of Securities Commissions ("IOSCO") led to IOSCO issuing two documents ${ }^{3}$ in 2003 concerning the activities of CRAs and the high-level principles that should govern them. Both papers emphasized the importance of ratings issued by CRAs in reducing information asymmetries in the market and took to task the means by which this objective can be promoted and protected, namely, by mechanisms that addressed matters such as conflicts of interest and transparency that could impact on the independence and objectivity of the ratings. In 2004 IOSCO published its "Code of conduct fundamentals for credit rating agencies" ("IOSCO CRA Code"). ${ }^{4}$ Taken together, these documents established, for the first time, a basis for an international standard to the regulation of CRAs. However, CRAs at this time remained self-regulated.

It was not until the global financial crisis of 2008 that there was an international consensus that CRAs should be brought under regulatory oversight. ${ }^{5}$ In September 2009 the European Union ("EU") issued a regulation on CRAs the purpose of which was, inter alia:

"to enhance the integrity, transparency, responsibility, good governance and reliability of credit rating activities ... [and to lay down] conditions for the issuing of credit ratings". ${ }^{6}$

\footnotetext{
${ }^{1}$ See generally: DW Arner et al, "Regulating Credit Rating Agencies in Hong Kong: Lessons from the Global Financial Crisis" Banking \& Finance Law Review 25.3 (June 2010), 361403, page 363; Herwig M. Langohr and Patricia T. Langohr, "The Rating Agencies and their Credit Ratings: What They Are, How They Work and Why They Are Relevant", 2008 John Wiley \& Sons Ltd, pages 1-2; A Duff and S Einig "Credit rating agencies: meeting the needs of the market?", The Institute of Chartered Accountants of Scotland, 2007, Chapter 2

2 DW Arner et al, "Regulating Credit Rating Agencies in Hong Kong: Lessons from the Global Financial Crisis" Banking \& Finance Law Review 25.3 (June 2010), 361-403, page 363

3 "Report on the activities of credit rating agencies", and "IOSCO Statement Of Principles Regarding The Activities Of Credit Rating Agencies", both issued in September 2003

${ }^{4}$ The IOSCO CRA Code is updated from time to time, the current version being dated March 2015. See IOSCO FR05/2015

5 "Declaration: Summit on Financial Markets and the World Economy", and the "The Global Plan for Recovery and Reform, London" - statements issued by the G20 leaders, 15 November 2008 and 2 April 2009, respectively

${ }^{6}$ Article 1, Regulation (EC) No 1060/2009 of the European Parliament and of the Council of 16 September 2009 on credit rating agencies
} 
The effect of the EU regulation was to establish, from 7 June 2011, three gateways that permitted the use of credit ratings in the EU for the purpose of complying with EU laws and regulations: (1) ratings issued directly under the EU regulation, (2) ratings endorsed by CRAs regulated under the EU regime as complying with requirements as stringent as in the EU, and (3) ratings issued under an equivalent regulatory regime.

\subsection{The position in Hong Kong}

Hong Kong's implementation of a CRA regime closely followed the approach taken internationally post 2008. The SFC's consultation paper initiating the legislative changes references ${ }^{7}$ the Group of Twenty ("G20") "Declaration on strengthening the financial system - London, 2 April 2009", which required that "all Credit Rating Agencies whose ratings are used for regulatory purposes should be subject to a regulatory oversight regime."

The SFC considered the international developments, particularly the U.S. and the EU, important to ensure "that the regime under which CRAs will be regulated in Hong Kong is generally consistent with the relatively uniform approach to regulation that appears to be developing internationally". 8 With a view to ensuring that credit ratings issued by CRAs based in Hong Kong were serviceable in the EU, Hong Kong implemented its regulatory regime to meet the EU's test of equivalence and/or stringency. ${ }^{9}$

Hong Kong's CRA regime became effective on 1 June $2011 .{ }^{10}$ It consisted of amendments to the primary legislation governing the securities industry, the Securities and Futures Ordinance cap 571 ("SFO"), that introduced a definition of "credit rating" and added, to the nine already in place, a new regulated activity, "Type 10: providing credit rating services". In addition, the Securities and Futures Commission ("SFC") issued the "Code of Conduct for Persons Providing Credit Rating Services" ("SFC CRA Code"), ${ }^{11}$ a non-statutory regulatory code concerned with the conduct of CRAs that supplements its more general "Code of Conduct for Persons Licensed by or Registered with the Securities and Futures Commission" ("SFC General Code"). The SFC CRA Code expressly states that it "is based on" the IOSCO CRA Code. ${ }^{12}$

The CRA regime is in some ways distinct within the overall framework of the SFO. A primary concern of the SFO is the transactions, agreements, recommendations and information arising in relation to listed securities (both debt and equity). This may be contrasted with the CRA regime, which is concerned with the concept of the creditworthiness of corporate bodies (whether or not listed), debt securities of public companies (whether or not the debt is listed and excluding their equity securities), and agreements to provide credit.

On 28 April 2014 the European Commission issued its implementing decision by which it recognized the legal and supervisory framework of Hong Kong as being

\footnotetext{
7 SFC's "Consultation Paper Concerning the Regulatory Oversight of Credit Rating Agencies", 19 July 2010, para 3

8 SFC's "Consultation Conclusions Concerning the Regulatory Oversight of Credit Rating Agencies", 29 October 2010, para 4

9 "Consultation Conclusions Concerning the Regulatory Oversight of Credit Rating Agencies", Securities and Futures Commission, 29 October 2010, para 4

${ }^{10}$ Securities and futures Ordinance (Amendment of Schedule 5) Notice, L.N. 28 of 2011

11 June 2011

12 SFC CRA Code, para 2, referring to the IOSCO CRA Code in effect at that time.
} 
equivalent to the EU regulations. ${ }^{13}$ The decision is subject to three conditions, the first of which requires that CRAs:

"must be subject to authorisation or registration and to effective supervision and enforcement on an ongoing basis ... On this basis, it should be considered that CRAs in Hong Kong are subject to authorisation or registration requirements equivalent to those laid down in Regulation (EC) No 1060/2009 and the Hong Kong supervisory and enforcement arrangements applicable to CRAs are effectively applied and enforced." (emphasis added). ${ }^{14}$

Obtaining the equivalence decision is therefore not a one-off passport but an ongoing obligation requiring the conditions to be maintained on an ongoing basis. In this regard, IOSCO has observed the need for supervisors to monitor the effectiveness of their CRA regime and any conflicts that may arise in the CRA regimes between different jurisdictions. ${ }^{15}$ These requirements shall become relevant to consider at a later stage of this paper. ${ }^{16}$

\subsection{The Moody's case in Hong Kong}

Hong Kong's CRA regime, particularly the scope of "credit rating" and "providing credit rating services", has recently been the subject of close regulatory examination.

On 11 July 2011, less than 6 weeks after the introduction of the CRA regulatory regime in Hong Kong, Moody's Investors Service Hong Kong Limited ("Moody's") published a report, the "Red Flags for Emerging-Market Companies: A Focus on China" (the "RF Report"). Although Moody's itself did not regard the RF Report as being a credit rating, the SFC did regard it as such and imposed regulatory penalties on Moody's in respect of alleged regulatory breaches.

Moody's appealed the matter to the Securities and Futures Appeals Tribunal (the "Tribunal"), a statutory body ${ }^{17}$ charged with hearing appeals in respect of certain decisions of the SFC. The Tribunal concurred with the SFC's view that the issue of the RF Report constituted a credit rating. ${ }^{18}$ The RF Report and the Tribunal's determination are introduced in Section 2.

Although the powers of the Tribunal are considerable, including certain powers that a Court of law does not possess, ${ }^{19}$ its determination is technically incapable of affecting the law as a result of the nature of the Tribunal insofar as it is not a Court of law. Nevertheless, its role in Hong Kong's regulatory architecture gives

\footnotetext{
${ }^{13}$ Specifically, Regulation (EC) No 1060/2009 of the European Parliament and of the Council on credit rating agencies. See Official Journal of the European Union, vol 57, 3 May 2014, page 76-78. The decision came into effect on 23 May 2014

${ }^{14}$ Official Journal of the European Union, vol 57, 3 May 2014, page 76-77

15 IOSCO "Regulatory Implementation of the Statement of Principles Regarding the

Activities of Credit Rating Agencies - Final Report" FR04/11 February 2011, page 38

${ }^{16}$ See Section 6.1.2

17 Established under Part XI of the SFO

${ }^{18}$ Moody's Investors Service Hong Kong Limited and Securities and Futures Commission, Application No. 4 of 2014; date of determination 31 March 2016. See http://www.sfat.gov.hk/english/determination/AN-4-2014-Determination.pdf

19 See section 219 of the SFO. For example, to receive evidence not admissible in a court of law and to compel evidence. The Tribunal has the same powers as the Court of First Instance to punish for contempt and may also register its orders with the Court of First Instance, under sections 221 and 226 of the SFO respectively.
} 
its determination significant weight and serves as guidance to both the industry and SFC.

Moody's has appealed the Tribunal's determination. Under Hong Kong's regulatory architecture, this will bring the case before the Court of Appeal, ${ }^{20}$ a body that is able to set legal precedent regarding the interpretation of terms defined by statute. The case before the Court is of considerable interest for a number of reasons.

It will be the first case heard against a regulated CRA in Hong Kong, and also the first time a determination of the Tribunal has been appealed under the appeal mechanism established when the SFO was introduced in 2003.

Of greater relevance to the purposes of this paper, it will also be the first occasion in which a Court of law in Hong Kong or internationally ${ }^{21}$ has had to consider the precise scope of the term "credit rating".

An issue of no less importance will be the impact of the Court's ruling on information providers in the market, and the positioning of Hong Kong in the international CRA context. There is a broad industry and international consensus on what credit ratings are and are not. Different jurisdictions have provided for similar, though not identical, definitions of "credit rating". Aligning the meaning and scope of the term is important given the sought-after consistency in the international approach to CRA regulation. The alignment of Hong Kong's statutory use of the term with international expectations, fundamental to the origins of CRA regulation in Hong Kong, ${ }^{22}$ is of particular relevance in view of the condition attached to the EU decision cited above, as will be discussed in Section 6.

In sum, the case has the potential to establish important boundary lines for the CRA industry domestically and internationally as well as for information flowing into the market more generally - what material should be regarded as research product and what falls to be treated under the special category of 'credit rating'.

\subsection{Structure of this paper}

Section 2 of this paper provides an overview of the issue of the RF Report, the applicable regulatory context, and the subsequent regulatory actions taken. The Tribunal's determination is outlined for more detailed consideration in subsequent sections.

Sections 3 to 5 comprise a detailed analysis of the Tribunal's determination, dealing with, in sequence, the purposive approach undertaken by the Tribunal, the means by which the Tribunal has construed the issuance of the RF Report as a credit rating and/or the provision of credit rating services, and the role of the press release issued the day the RF Report was issued.

\footnotetext{
20 Part XI, Division 3 of the SFO

${ }^{21}$ Searches were conducted using Lexis in Hong Kong, the UK, all EU member states, US Federal courts, Canada and Australia. However, two cases of interest for other reasons were identified and these are discussed elsewhere in this paper, namely, Bathurst Regional Council v Local Government Financial Services Pty Ltd (No 5) 3 of 6 (2012) and General Electric Capital Canada Inc. v. Canada, [2009] T.C.J. No. 489 (Tax Court appeal).

22 I.e. the desire to achieve a "relatively uniform approach" (SFC's "Consultation Paper Concerning the Regulatory Oversight of Credit Rating Agencies" 19 July 2010, para 4) with that taken internationally. See also para 7 of the SFC's "Consultation Conclusions Concerning the Regulatory Oversight of Credit Rating Agencies" 29 October 2010
} 
Section 6 considers the implications of the Tribunal's determination should it be upheld in the Court of Appeal, in particular, whether it may be counterproductive to the policy intent of the Legislature.

Sections 7 and 8 conclude.

\section{THE HONG KONG CASE}

\subsection{The RF Report}

The RF Report was issued as a paid-for product, however, it quickly became freely available in the market. ${ }^{23}$ It comprised a framework in which red flags were assigned to specified companies across a range of corporate governance and accounting risk issues. The framework comprised 20 red flags grouped into five categories that are described as "screens for governance or accounting risks [that] can help identify areas to investigate but cannot serve as mechanisms to rank order credit risk. ${ }^{\prime 24}$, The categories, explained in an appendix to the report, are:

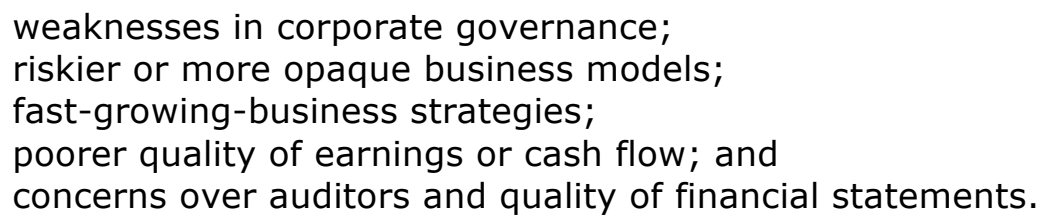

The RF Report describes the system as identifying "warning signs" for the types of companies covered, being 61 Chinese non-financial companies that fall within Moody's ratings horizon as being "high-yield". ${ }^{25}$

A summary of how many red flags were raised on a category-by-category basis against each company's credit rating. The report noted in several places that there was "limited correlation" 26 between the number of red flags and the credit ratings that had been assigned to the companies under Moody's existing ratings, which ranged from Ba1 to Caa2.

Six of the companies, that had triggered between 7 and 12 red flags, were identified as "negative outliers"27 and were subject to additional comments as to "what risks these flags are highlighting." 28 The RF Report does not explain why these companies were identified as negative outliers when other companies also triggered the same number of flags.

\subsection{The regulatory context}

Moody's holds a Type 10 license (providing credit rating services). That regulated activity is defined as meaning:

"(a) preparing credit ratings-

(i) for dissemination to the public, whether in Hong Kong or elsewhere; or (ii) with a reasonable expectation that they will be so disseminated; or

\footnotetext{
${ }^{23}$ The RF Report can be found on the internet by searching for it.

${ }^{24}$ RF Report page 1

${ }^{25}$ RF Report page 2

${ }^{26} \mathrm{RF}$ Report pages 1 and 4

${ }^{27}$ RF Report pages $14-15$ of Appendix 2

${ }^{28}$ RF Report page 4
} 
(b) preparing credit ratings-

(i) for distribution by subscription, whether in Hong Kong or elsewhere; or (ii) with a reasonable expectation that they will be so distributed" (emphasis added) ${ }^{29}$

As such, when Moody's engages in Type 10 regulated activity it is subject to SFC General Code and the SFC CRA Code. Both codes are concerned with conduct matters. The latter code, which is based on the IOSCO CRA Code, ${ }^{30}$ is specifically concerned with matters covering CRAs including the rating process, independence and conflicts of interest including the undertaking of ancillary services, and the responsibilities of a CRA to the investing public and rated entities.

Under the foregoing definition, the question of whether a person engages in Type 10 regulated activity turns on the question of whether or not the information disseminated is or is not a "credit rating", defined by the SFO as meaning:

"opinions, expressed using a defined ranking system, primarily regarding the creditworthiness of- (a) a person other than an individual; (b) debt securities; (c) preferred securities; or (d) an agreement to provide credit" ${ }^{31}$

This definition will be examined in closer detail in Sections 3 and 4 of this paper. For present purposes it is sufficient to note that if the RF Report is a credit rating, then it is clear that Moody's when issuing it was engaging in Type 10 regulated activity. If it is not, then, on a straightforward reading of the ordinance, whatever activity it might be regarded as, it would appear not to be Type 10 regulated activity.

\subsection{The SFC's position}

The SFC regarded the issue of the RF Report as subject to its regulatory jurisdiction. This was because either (1) the RF Report was itself a credit rating so that when Moody's issued it, it was engaging in Type 10 regulated activity, or (2) if not, the issue of the RF Report was so "closely attendant upon [Moody's Type 10 activities that it] must be subject to the disciplinary jurisdiction of the SFC. ${ }^{132}$

As such, the issuance of the RF Report would be subject to both the SFC CRA Code and the SFC General Code. The SFC considered Moody's to have breached, inter alia33, the following two general principles of the SFC General Code and exercised its power ${ }^{34}$ to impose a fine of $\mathrm{HK} \$ 23$ million:

"General Principle 1: Honesty and fairness

In conducting its business activities, a licensed or registered person should act honestly, fairly, and in the best interests of its clients and the integrity of the market.

General Principle 2: Diligence

\footnotetext{
${ }^{29}$ SFO Schedule 5, Part 2. The definition also contains exemptions not relevant to the Moody's case

30 SFC CRA Code para 2

31 SFO Schedule 5, Part 2

32 Determination of the Securities and Futures Appeals Tribunal (the "Determination") para 66

${ }^{33}$ The SFC had also alleged a breach of para 4.3 of the SFC General Code concerned with internal controls and operational resources, however, the Tribunal struck down that allegation.

${ }^{34}$ Under section 194 of the SFO
} 
In conducting its business activities, a licensed or registered person should act with due skill, care and diligence, in the best interests of its clients and the integrity of the market. ${ }^{\prime \prime 35}$

To the above summary, it is of interest to note three things.

First, at the time of the introduction of the SFC CRA Code, there was some discussion, and lack of clarity in the market, as to what provisions of the SFC General Code are intended to apply to CRAs, or how such provisions are intended to be applied. For example, certain provisions appear not to be relevant to CRAs, ${ }^{36}$ while other provisions are in effect superseded by the more specific provisions of the SFC CRA Code. ${ }^{37}$

Second, that the disciplinary action brought by the SFC was based on the SFC General Code. The more specifically targeted SFC CRA Code, surprisingly, was not cited in the SFC's disciplinary action.

Third, something that will be returned to in subsequent sections of this paper, that the SFC and the Tribunal referred to the effect of the RF Report in the debt and equity markets. In particular, it was observed that the share price of "more than half of the issuers red-flagged in the [RF] Report had experienced substantial falls. ${ }^{\prime 38}$ Much seemed to be made of this effect in the market.

\subsection{The Tribunal's determination ${ }^{39}$}

Moody's appeal of the SFC'S disciplinary action brought before the Tribunal the central question of whether the SFC had jurisdiction over the issue of the RF Report: "[I]n terms of the relevant statutory provisions, did the publication of the [RF] Report (of itself) constitute the provision of credit rating services?" ${ }^{\prime 40}$ Only if the answer to that question was in the positive would the SFC have jurisdiction over Moody's in relation to the RF Report. ${ }^{41}$

The Tribunal's analysis, in brief overview, is as follows.

The Tribunal observed that "the greater number of red flags ... the greater the number of warning signs, the greater the need on the part of market participants for scrutiny. ${ }^{\prime 42}$ It had little difficulty in finding the red flag framework comprised a "well-defined system or mechanism for judging levels of credit risk" ${ }^{43}$ in which the number of red flags assigned to a company reflecting a ranking of risk, ${ }^{44}$ and noted that Moody's described the red flag mechanism to be a method that could be applied more widely to other corporates. ${ }^{45}$ It was "clearly a system that

\footnotetext{
35 SFC General Code page 1.

${ }^{36}$ General Principles 4 and 8; para 3.4 since CRAs provide opinions as distinct from giving advice; and Schedule 2

${ }^{37}$ For example, para 3.10

38 Determination para 37

39 The Determination can be found at http://www.sfat.gov.hk/english/determination/AN-42014-Determination.pdf

40 Determination para 80

${ }^{41}$ Although not addressed by the Tribunal (due to the scope of its function), the SFC may nevertheless have powers in relation to the RF Report qua information in the marketplace - this is discussed in Section 5 below.

42 Determination para 93

43 Determination para 93

44 Determination para 92

45 Determination para 90
} 
assessed elements of credit risk by a form of ranking. ${ }^{146}$ In these regards the Tribunal also noted that the report was said to be "actionable", an expression taken as meaning that it was capable of giving rise to some form of action. ${ }^{47}$ The RF Report presenting itself as an actionable methodology - i.e. a system. ${ }^{48}$

The Tribunal also expressed the view that "the red flag framework operated on the basis that the greater the number of flags triggered the greater the potential credit risk". ${ }^{49}$ Its own summary connects the red flag system exclusively to credit risk: ${ }^{50}$

the red flags "constituted a warning sign of potential credit risk";

the categories outlined "elements of potential credit risk";

therefore, a higher number of flags represented higher "potential credit risk" and the allocation of no red flags meant "within the scope of the framework, no credit risk element"; and

the framework was applicable to "high yield companies".

The Tribunal, taking the view that "the phrase 'credit ratings' is broadly defined" ${ }^{51}$ determined that the RF Report either is itself a credit rating, or, if it is not, then it is "part and parcel of Moody's ratings themselves" on the basis that the RF Report is intended to amplify and supplement, and is "intimately attendant upon", Moody's credit ratings. ${ }^{52}$ Accordingly, Moody's "preparation and publication of the red flag framework fell within the statutory definition of regulated activities", ${ }^{53}$ and was subject to the SFC's codes and disciplinary powers arising in relation thereto. The SFC's fine was reduced from HK\$23 million to HK\$11 million, a public reprimand, and a costs sharing order. Moody's has since lodged an appeal that will take the matter to the Court of Appeal.

The foregoing overview of the Tribunal's determination will be expanded upon in the following sections. Section 3 examines the Tribunal's purposive approach to interpreting the relevant law, Section 4 examines its view that "credit rating" is broadly defined, and Section 5 examines its treatment of the press release.

\section{THE TRIBUNAL'S APPROACH}

The central issue before the Tribunal was essentially one that required interpretation of legislation, namely, the provisions in the SFO defining the extent and scope of Type 10 regulated activity. This would determine the proper reach of the SFC's regulatory jurisdiction.

The introduction of the CRA regime in Hong Kong being relatively new, there is no judicial precedent on the matter. Nor does there appear to be any judicial ruling internationally that might be of assistance. ${ }^{54}$ Accordingly, the Tribunal undertook a purposive interpretation of the relevant provisions, noting this requires "that the language of a statutory provision is to be construed having regard to its context and purpose" (emphasis added). ${ }^{55}$ The Tribunal cites HKSAR $v$ Cheung

\footnotetext{
46 Determination para 96

47 Determination para 101

48 Determination para 152

49 Determination para 31

50 Determination para 92

51 Determination para 81

52 Determination para 102

53 Determination para 102

54 See footnote 21 above

${ }^{55}$ Per Mr Justice Fok PJ in Pacific Sun Advisors Ltd and Another v. Securities and Futures

Commission [2015] HKCFA 27 at para 34
} 
Kwun Yin ${ }^{56}$ that under such an approach statutory language is to bear its "natural and ordinary meaning unless the context or purpose points to different meaning". ${ }^{57}$

This Section 3 raises questions over three central aspects of the Tribunal's purposive approach: (1) the entry point for its analysis, (2) its reliance on factors lying outside the four sides of the RF Report, and (3) its consideration of the SFC's regulatory jurisdiction from a disciplinary perspective. In each of these aspects it will be seen that an underlying position of the Tribunal is that the RF Report is connected with or related to Moody's existing credit ratings - that facet of the Tribunal's determination is discussed in Section 4.

\subsection{Entry point for application of the purposive approach}

The Tribunal posited the core question for its interpretative exercise as being: "did the publication of the [RF] Report (of itself) constitute the provision of credit rating services? ... In determining this issue it is important to note that the phrase 'credit ratings' is broadly defined."

The natural and ordinary reading of the definition of Type 10 regulated activity is that it can only occur in respect of credit ratings. Accordingly, the first matter that would seem to require consideration is whether an item of information is or is not a credit rating - only if it is would it seem relevant to consider the further requirements attaching to Type 10 regulated activity.

This is consistent with the international context being primarily concerned with the quality of credit ratings themselves - the means by which the G20 envisaged that would be safeguarded was via a registration system and a regulatory oversight regime consistent with the IOSCO CRA Code. ${ }^{59}$ That regulatory oversight of CRAs is the means by which the quality of credit ratings is strengthened is also reflected in Article 1 of the EU regulations. ${ }^{60}$ Accordingly, the approach internationally has been to use regulatory definitions that build on each other, namely, a definition of 'credit rating' and a definition of 'credit rating agency'.

Different jurisdictions have implemented CRA regulation in a way that fits into their own legal and regulatory architecture but nevertheless achieves sufficient consistency with the approach internationally. In Hong Kong, the means by which the primary objective of bringing credit ratings under regulatory oversight was via the creation of the Type 10 regulatory activity. ${ }^{61}$

As noted above, the Tribunal considers the term "credit rating" to be broadly defined, sufficiently so that it does not undertake any detailed analysis of the term. Rather, its focus settles on the regulated activity. Section 4 below argues that "credit rating" in fact carries a specific meaning and that the Tribunal has glossed over important differences between elements that pertain to credit risk, the concept of creditworthiness, and the opinion that is expressed on

${ }^{56}$ (2009) 12 HKCFAR 568

57 Ibid. Per Chief Justice Li at para 12

${ }^{58}$ Determination para 80-81

59 Group of Twenty (G20) "Declaration on strengthening the financial system - London, 2 April 2009"

${ }^{60}$ EU Regulation (EC) No 1060/2009

${ }^{61}$ This approach is similar to the NRSRO system in the U.S. in which CRAs are recognized by the relevant authorities - see DW Arner et al, "Regulating Credit Rating Agencies in Hong Kong: Lessons from the Global Financial Crisis" Banking \& Finance Law Review 25.3 (Jun 2010): 361-403, page 369 
creditworthiness. If the argument in Section 4 is correct, it would be erroneous to take Type 10 regulated activity as a focal point for the determination without first examining whether the information issued was in fact a credit rating. (It should be added here that the Tribunal does accept an alternative view that even if the RF Report and the red flag framework was not itself a credit rating it is nevertheless part and parcel of Moody's credit rating services - this is discussed in Sections 3.3 and 5 of this paper.)

\subsection{Consideration of extrinsic factors}

In determining the nature of the report and Moody's issuance of it, the Tribunal considered the following factors lying outside the four sides of the RF Report: (1) Moody's intended purposes ${ }^{62}$ in issuing the RF Report, ${ }^{63}$ (2) its effect in the equity and debt markets, ${ }^{64}$ and (3) the press release issued the day the RF Report was issued. ${ }^{65}$

The language of Hong Kong's statutory CRA regime is silent as to such extrinsic factors. An examination of other provisions of the SFO dealing with regulatory objectives similar to those sought under the CRA regime indicate that where the Legislature has chosen to bring extrinsic matters within the scope of a provision, it has done so clearly and with good reason. Considering other provisions of the SFO is consistent with the purposive approach when seeking "to determine whether any conclusions can be drawn as to ... legislative intent." ${ }^{66}$ Per Chief Justice Li, "The context of a statutory provision should be taken in its widest sense and certainly includes the other provisions of the statute and the existing state of the law. ${ }^{\prime 67}$ The analysis in Sections 3.2.1 to 3.2.3 questions whether the Legislature intended such extrinsic matters to be relevant to the CRA regime.

\footnotetext{
${ }^{62}$ Per the Tribunal (all para references are to the Determination): "as to the nature and purpose of" the RF Report (para 19); "the purpose [of the RF Report] being to highlight..." (para 21); "In the present case, it is submitted that the nature and purpose of the [RF] Report was so closely allied to and so immediately consequent upon Moody's Type 10 regulated activities that..." (para 66); "whether it was intended by Moody's or not, the red flag framework ... constituted a credit rating" (para 93); the intent to produce something 'actionable' (para 100-101) and "the intended meaning of the word 'actionable'" (para $152)$; "it is evident that it was intended to be read as amplifying and supplementing Moody's ratings" (para 102); "those responsible for compiling the Report intended that it should be more than a mere comment piece" (para 130); the discussion of whether or not it was "intended to add anything to the existing ratings" (para 147); the red flags were "intended to impact on the market and they did so" (para 193); "a report that was intended to have an impact on the market" (para 214)

${ }^{63}$ The Tribunal considers a number of Moody's internal communications, including in several paragraphs of the determination specifically addressed to the "genesis of the report", see Determination para 124 to 133

${ }^{64}$ Per the Tribunal (all para references are to the Determination): the RF Report "was clearly intended for the market... it was intended to have an impact" (para 3); "The [RF] Report was published at a time of considerable concern in the market as to" (para 18); the discussion at para 29; "more than half of the issuers red-flagged in the Report had experienced substantial falls. Four of the six issuers identified in the Report as negative outliers suffered the biggest drops" (para 37); "In the judgment of the Tribunal, Moody's must have appreciated in such circumstances that in all probability the Report would have a material impact on the market, that is, an impact of consequence" (para 42); the red flags were "intended to impact on the market and they did so" (para 193); "a report that was intended to have an impact on the market" (para 214)

${ }^{65}$ The press release can be found here (last accessed May 2016)

https://www.moodys.com/research/Moodys-Accounting-and-governance-warning-signsfor-emerging-market-companies--PR_222323

${ }^{66}$ Pacific Sun Advisors Ltd and Another v. Securities and Futures Commission [2015] HKCFA 27; Facc 11/2014 (20 March 2015) at para 25

${ }^{67}$ Cheung Kwun Yin op. cit. at para 13
} 
That it might not be the intent of the Legislature is consistent with the international origins of CRA regulation in Hong Kong, as discussed in Section 3.1 above, which takes as it primary focus the quality of the credit rating as an item of information.

\subsubsection{Issuer's intent}

When defining the scope of regulated activities, the SFO is clear about the role of intent. The two other regulated activities that centrally involve the dissemination of information to clients or to the public are advising on securities (Type 4 regulated activity) and advising on futures contracts (Type 5 regulated activity). The definition of both activities includes "issuing analyses or reports, for the purposes of facilitating the recipients of the analyses or reports to make decisions" (emphasis added). ${ }^{68}$ In construing those definitions, the purpose and intended use of the relevant material will be relevant to consider.

This may be contrasted with the definition for "providing credit rating services" (Type 10 regulated activity), which refers only to "preparing credit ratings ... for dissemination to the public... or for distribution by subscription". ${ }^{69}$ There is no reference as to the intended purpose or use of the credit rating.

Unlike Types 4 and 5 regulated activities in which the phrase "analyses or reports" is not specifically defined by the SFO (and which presumably take on their ordinary meaning), Type 10 regulated activity specifically refers to "preparing credit ratings" - the term "credit rating" having been expressly defined by the SFO. That term also contains no element of intent or purpose, only the nature of the material qua opinion needs to be considered.

Intention has a very limited and precise scope of relevance in the CRA regime - if the material was in fact a credit rating one can then consider the rudimentary matter of whether there was an intention to disseminate or distribute the material. ${ }^{70}$ To put this another way, intent alone seems incapable of changing the nature of information that has been distributed.

That the language of intended purpose is used in respect of Type 4 regulated activity but not Type 10 is of particular interest in view of concerns, expressed during the SFC's public consultations on the proposed legislative changes that:

"the issuing of credit ratings will be distinguishable from Type 4 regulated activity (advising on securities), even in the case of broker recommendations using a defined ranking system (such as "buy", "hold" or "sell"). Advising on securities may include providing opinions on a company's creditworthiness, but only as a factor impacting upon advice on whether (or which, or the time at which, or the terms or conditions on which) securities should be acquired or disposed of. By contrast, credit

\footnotetext{
68 SFO Schedule 5, Part 2

69 SFO Schedule 5, Part 2

${ }^{70}$ It is for this reason that although one might, for example, intend to disseminate a document believing or intending that it is a credit rating, if the document is not in fact a credit rating (for example, it is merely advice) then the issuer of the document is not actually 'providing credit rating services' although it may be holding itself out to be so. I.e., if the issuer is not licensed for Type 10 regulated activity this would be an offence under section 114(1)(b) but not section 114(1)(a) of the SFO. The act of holding out clearly is incapable of affecting the nature of the report.
} 
ratings, as typically understood, do not include advice on whether securities should be acquired or disposed of. ${ }^{\prime 71}$

As regards the broader context of legislative origin, the distinctions made in the SFO reflect the international approach to CRA regulation in which an issuer's intended purpose or expected use of information issued by them plays no role.

\subsubsection{Consequences in the market}

There seems no doubt both the debt and equity market did in fact respond to the release of the RF Report, and as noted above the Tribunal refers to this on several occasions. While there also seems little doubt that Moody's intended the RF Report to be utilized by market participants, the issue of intent vis-à-vis the nature of the report has been dealt with above.

Share prices can respond to changes in debt ratings ${ }^{72}$ but they also respond to a variety of new types of information coming into the market. As noted by the Tribunal, "credit ratings are important because they enable market participants to employ these opinions as screening devices to match the relative credit risk of issuers of debt instruments with their own risk tolerance. ${ }^{\prime 73}$ However, the core question for the purposes of statutory interpretation is whether market reactions are relevant to determining whether a report, such as the RF Report, is a credit rating or the issuance of it Type 10 regulated activity.

A central concern of the SFO is to safeguard the integrity of the market. It contains several mechanisms designed to that purpose including controls over access to the market. Defining certain types of services as regulated activities that are subject to the regulatory jurisdiction of the SFC, including that of CRAs, is one such mechanism. Another is concerned with the dissemination of information into the market and a credit rating once issued also constitutes information in the market. Again having regard to the process of interpretation undertaken in Pacific Sun and the purposes of the legislation (see also Section 6.2 below), these market-oriented information provisions are also relevant to consider.

The SFO is specific as to when expectations, responses or effects in the market are to be taken into account to meet its legislative purposes. Sections 277 and 298 of the SFO, both concerned with the disclosure of false or misleading information inducing transactions, requires that the information "is likely" to induce transactions or maintain, increase, reduce or stabilize prices in securities or futures contracts. ${ }^{74}$ Civil liability in respect of disseminated information also specifically requires that the information "may affect" prices. ${ }^{75}$ The concept of inside information for the purposes of both insider dealing legislation and the disclosure obligations of listed companies ${ }^{76}$ is also expressly tied to the concept that the information would "be likely to materially affect the price of the listed securities". ${ }^{77}$

\footnotetext{
${ }^{71}$ SFC's Consultation Paper Concerning the Regulatory Oversight of Credit Rating Agencies, 19 July 2010, para 16

${ }^{72}$ For example, see Barron MJ, Clarke AD and Thomas SH, "The effect of bond rating changes and new ratings on UK stock returns", Journal of Business Finance and Accounting, 1997, vol 24, p497-509

73 Determination para 12

74 Section 277(1)(c) and 298(1) of the SFO

75 section $391(1)(b)$ of the SFO

76 Relevant to Parts XIII, XIV and XIVA of the SFO

77 Sections 245(2), 285(2) and 307A(1) of the SFO
} 
In contrast, neither Type 10 regulated activity nor any of the other regulated activities are concerned with effects in the market. This reflects the nature of Hong Kong's regulatory architecture which provides for classes of regulated activity that are defined by the acts undertaken not by the consequences of acts. Consequences are the concern of other provisions of the SFO. Accordingly, if the market had exhibited no response to the RF Report, this also would not impact on whether or not the report was a credit rating.

The SFO's different concerns with market integrity as regards information that flows into it, and market integrity as regards the activities that take place in the market, are distinct and reflect the fundamental structure of its architecture. Observing this design in applying the law to facts is critical for the proper operation of the SFO.

\subsubsection{The press release}

The Tribunal cites the press release issued the day the RF Report was published as relevant to an understanding of "the nature and purpose" is part of its finding that the RF Report was "part and parcel"79 of Moody's existing credit ratings, and considers that the press release conditioned readers in such a way as to influence their reading and understanding of the RF Report. It therefore forms part of the means by which the Tribunal considered Moody's to have engaged in Type 10 regulated activity when it issued the RF Report.

The Tribunal states that "The press release explained that the red flag framework was 'supplemental to' Moody's methodological approach to rating" ${ }^{\prime 80}$ and suggests that the word "supplemental" served to import the meaning that the red flags added to and/or amplified Moody's existing credit ratings. ${ }^{81}$ It also notes the SFC considered the press release as relevant. ${ }^{82}$ According to the SFC, the press release forms part of "the impression being created that the red flag framework was a part of Moody's established methodology" 83 and that the RF Report and press release "created confusion". ${ }^{84}$

However, the Tribunal does not cite any legislative or other legal basis on which it is appropriate to consider the press release as relevant to the nature of the RF Report or the question of Type 10 regulated activity.

The SFO itself neither provides for nor limits the form or documentary basis on which a credit rating opinion is to be expressed. Certainly, the press release itself is incapable of expressing an opinion insofar as nothing is expressed on any specific rating target. Nor does the SFO provide for the deemed incorporation into a rating opinion of statements made at the time of issue of a credit rating. This may of course be relevant for other purposes in the SFO (e.g. provisions dealing with the integrity of information disseminated in the market) but it is not provided for in the CRA context. That this is so is again consistent with the international approach to CRA regulation which is focussed on the quality of the opinion that has been given and the general understanding, reflected in the SFC

\footnotetext{
78 Determination para 19

${ }^{79}$ Determination para 74 and 102

80 Determination para 21. See also Determination para 153

81 Determination para 32

82 In its Notice of Proposed Disciplinary Action dated 14 February 2013, as cited in the Determination

${ }^{83}$ Determination para 51(a), See also Determination para 45

${ }^{84}$ See Determination para 148 citing the SFC's Decision Notice Notice of Proposed

Disciplinary Action dated 14 February 2013
} 
CRA Code ${ }^{85}$ that ratings are expressed via a defined ranking system comprised of well defined and consistently used symbols (such as AAA, AA, etc.). The topic of defined ranking systems is further discussed in Section 4.3.1.

The SFC CRA Code does in fact require a CRA to issue a press release when issuing or revising a credit rating that explains the key elements of the rating. ${ }^{86}$ However, there is also nothing in the SFC CRA Code suggesting such an explanation in any way affects or is to be read together with the credit rating. The two remain quite separate items attending different purposes. Press releases may of course be issued by CRAs for other purposes not connected with their regulated activities.

The position in relation to CRA regulation contrasts with the Legislative approach taken in respect of another form of information-bearing document issued to the public, namely, prospectuses. In that context the governing legislation ${ }^{87}$ contemplates that a prospectus may be comprised in multiple documents, ${ }^{88}$ that statements may be incorporated by reference or issued together with a prospectus, $^{89}$ and that other public notices may affect liability arising in connection with a prospectus. ${ }^{90}$

This leaves considerable uncertainty as to the precise basis on which the press release has been incorporated by reference for the purposes of defining whether or not a regulated activity has been engaged in. The press release is further discussed in Section 5 below where it is argued that even if the press release is appropriate to consider, it nevertheless does not have the import alleged by the Tribunal.

\subsubsection{Conclusion}

While it might seem quite natural to enquire of the matters surrounding the publication of the RF Report, Sections 3.2.1 to 3.2.3 raise a number of doubts over the Tribunal's consideration of, and approach to them.

That the handling of credit rating activities under the SFO is somewhat different from other parts of the SFO concerned with regulated activities or the quality of information in the market is traceable back to the originating purposes for bringing CRAs under regulatory oversight.

\subsection{Regulated and non-regulated services}

As noted in Section 3.1, the purposive approach taken by the Tribunal brings emphasis to the activity rather than the "credit rating" question per se. In doing so it also places some emphasis on the SFC's powers under section 194 of the SFO to impose disciplinary action where a regulated intermediary has engaged in misconduct, which includes any

"act or omission relating to the carrying on of any regulated activity ... which, in the opinion of the [SFC], is or is likely to be prejudicial to the

\footnotetext{
${ }^{85}$ Para 53

86 Para 55

87 Companies (Winding-up and Miscellaneous Provisions) Ordinance, cap. 32 ("CWUMPO")

88 Section 39B of the CWUMPO

${ }^{89}$ Section $41 \mathrm{~A}(1)(\mathrm{b})$ of the CWUMPO. It can also be noted that section 2(1) of the CWUMPO also covers documents that are "calculated to invite offers"

${ }^{90}$ Sections $40(2)$ and (3)(b) of the CWUMPO
} 
interest of the investing public or to the public interest" (emphasis added). ${ }^{91}$

As already noted (and which will be queried in Section 4), the Tribunal's position is that the RF Report is connected to Moody's existing ratings. As such, "in giving a purposive construction to the relevant statutory provisions, the act of publication [of the RF Report] must be held to be an act relating to those earlier ratings." ${ }^{\prime 2}$ The Tribunal observes that the phrase "relating to" is "capable of bearing a broad or narrow meaning in order to further the legislative purpose."

There is a sense in which the invocation of sections 193 and 194 rests on an almost tautological presumption that the act complained of already falls within some broad scope of an intermediary's regulated activities, which is precisely the matter in issue. The separation of "relating to" as a proposition in the line of reasoning merely represents the dénouement of the tautology. However, putting aside that disquiet, the reason for the Tribunal electing a broad reading of the phrase is not clear, nor is it clear whether such a reading furthers or in fact hinders the legislative purpose. The Tribunal's broad reading of the phrase gives rise to several issues.

First, it implies that various acts that are not part of a "regulated activity" would not be regarded as misconduct when undertaken by a person who holds no license or registration, but might be if exactly the same acts were undertaken by a person who is licensed or registered. That the regulatory nature of an act should be determined by the identity of the person undertaking the act, not the act itself, is inconsistent with Hong Kong's regulatory architecture and seems to offend the principle of a level playing field. It creates the problem that if an unregulated person had issued the RF Report, the issuer of it would not be subject to the same regulatory powers of the SFC as Moody's - while the unregulated person might have committed some other breach of the law, ${ }^{94}$ this will not always be the case.

Second, it is at odds with the phrase being essentially limited by the requirement that it must relate to "the carrying on of any regulated activity". A relationship to other business activities would not suffice. For example, section $27(1)$ (b) of the SFO, dealing with records of Hong Kong Exchanges and Clearing Limited refers to "information relating to its business". In contrast, the language of section 193 does not broadly refer to a regulated person's business but only to its regulated activities There are a number of other provisions in the SFO that are similarly limited. ${ }^{95}$

Third, given that "relating to" is somewhat imprecise, a broad reading may create considerable uncertainty among regulated persons insofar as any non-regulated act they undertake might subsequently be construed as "related to" their regulated activities without any clear legal or regulatory guidelines on the matter. However, the SFO already contemplates guidance as to a regulated person's undertaking - the SFC is empowered to make codes of conduct "for the purpose of giving guidance relating to the practices and standards with which [regulated persons] are ordinarily expected to comply in carrying on the regulated activities

\footnotetext{
${ }^{91}$ Section $193(1)(d)$

92 Determination para 106

93 Determination para 106

94 For example, holding itself out as engaging in a regulated activity or distributing false information

${ }^{95}$ For example, see section 113 of the SFO, definition of "regulated function" which is similarly restricted to regulated activities
} 
for which the intermediaries are licensed or registered" (emphasis added). ${ }^{96}$ This language does not sit comfortably with a broad reading of "relating to" in section $193(1)(d)$ of the SFO, the application of which first requires regard to be had to the SFC's codes of conduct. ${ }^{97}$ Indeed, the SFC's codes do not appear to carry such a wide remit that they address activities that are not themselves regulated there would be no legislative basis for the codes to do so.

Fourth, the above concerns suggest that the Tribunal's reading could significantly blur the tight lines drawn by the SFO around specific types of activity as being regulated. In the context of the introduction of the CRA regime, the SFC emphasized during consultation process the necessity to keep regulated activities distinct from each other and, in particular, to "effectively distinguish between Type 4 and Type 10 regulated activities". ${ }^{98}$ If the definition of "providing credit rating services" is drawn uncertainly then one must consider whether the provision would continue to serve its purpose. Moreover, as those consultation papers constitute recommendations made by a statutory body that are subsequently implemented in the legislation, they may properly be taken into account when identifying the purpose of legislation. ${ }^{99}$

Finally, returning to the purposive approach, Chief Justice Li has stated "The context of a statutory provision should be taken in its widest sense and certainly includes the other provisions of the statute and the existing state of the law."100 This requires a consideration of the SFO as a whole and asking whether a particular interpretation is necessary or desirable having regard to its purposes. In this regard it may be observed that other parts of the SFO amply address acts that do not themselves comprise regulated activities. Significant portions of the SFO are concerned with acts related to information that may impact on the integrity of the market and that apply irrespective of a person's regulated status. ${ }^{101}$

It is suggested the Tribunal's broad reading of the phrase is not needed to meet the purposes of the legislation, and that it instead gives rise to greater problems.

Section 6.2 below discusses the information-related provisions of the SFO that may be relevant to the RF Report.

\subsection{Conclusions on the Tribunal's purposive approach}

The foregoing considerations raise doubts over whether the Tribunal's approach is "purposive" or in fact "results oriented", reflecting a concern expressed by Lord Millet NPJ ${ }^{102}$ as regards the use and misuse of the purposive approach. Whatever the intention of the Legislature may have been, the purposive approach is ultimately restricted to seeking the meaning of the words the Legislature has in

\footnotetext{
96 Section 169(1) of the SFO

97 Section 193(3) of the SFO

98 SFC's "Consultation Conclusions Concerning the Regulatory Oversight of Credit Rating Agencies", 29 October 2010, para 22

99 Per Chief Justice Li at para 14 of Cheung Kwun Yin op. cit.: "Where the legislation in question implements the recommendations of a report, such as a Law Reform Commission report, the report may be referred to in order to identify the purpose of the legislation." ${ }^{100}$ Cheung Kwun Yin op. cit. at para 13

101 Including sections 107, 108, 391 and Parts XIII, XIV and XIVA of the SFO

102 "there has been a distressing development by the courts which allows them to distort or even ignore the plain meaning of the text and construe the statute in whatever manner achieves a result which they consider desirable" [2009] 5 HKC 231, para. 36 and (2009) 12 HFCFAR 342
} 
fact used. ${ }^{103}$ It is therefore suggested the language used in the SFO does not in fact support the purposive interpretation employed by the Tribunal.

The Tribunal's approach sits uncomfortably with the hierarchy of the terms defined by the SFO which, on a natural and ordinary reading, recognizes it is not the case that all activities of Type 10 licensed corporations are regulated - only the credit ratings it issues are. This underpinned Moody's argument before the Tribunal that the SFC had no jurisdiction over the RF Report.

In common with the approach taken internationally, Hong Kong's CRA regulatory architecture implicitly recognizes the origins of CRAs are historically borne out of business analysis and that modern day CRAs can and do issue research that amounts to business analysis. ${ }^{104}$ Accordingly, Hong Kong's legislation does not prohibit a CRA from engaging in ancillary services, ${ }^{105}$ and the SFC CRA Code expressly permits it subject to the requirement that it does not create a conflict of interest for its credit rating services. ${ }^{106}$ It is also expressly permitted by EU regulations provided the independence or integrity of the CRA is not compromised. ${ }^{107}$ The EU regulations also clarify that ancillary services are not part of credit rating activities. ${ }^{108}$

Such analyses and ancillary services are not normally regarded as credit ratings notwithstanding that they may discuss elements relevant to assessments of credit risk, and that they may address specific corporate situations. Indeed, Moody's issues a variety of research documents that are not treated as credit ratings. ${ }^{109}$ The distinction between a discussion of elements of credit risk and giving opinions on creditworthiness is an important one to make, though at times appears muddled in the Tribunal's determination. This distinction is further discussed in the next section.

In view of the foregoing considerations, it is not consistent with either the development of the CRA regulatory regime or the structure and purpose of the SFO to frame an investigation into whether or not a credit rating has been issued by looking to the issuer's licensed status to determine the nature of a report it has issued. That would be the wrong starting point. Nor is it appropriate to selectively look at acts and consequences from a remedial point of view without considering other remedial provisions of the SFO that are arguably more clearly relevant to the alleged wrongdoing. ${ }^{110}$

Rather, insofar as the scope of the CRA regulatory regime is concerned, one must start by looking at the information that has been issued and ask whether or not it meets the statutory requirements for being a "credit rating". Section 4 undertakes such an analysis.

\footnotetext{
103 Per Lord Reid in Black-Clawson International Ltd v Papierwerke WaldhofAschaffenburg AG [1975] AC 591 at 613G, cited with approval in Cheung Kwun Yin op. cit. 104 Langhor page 2

105 The SFC, in line with international practice, rejected the concept that CRAs should be subject to a sole business restriction. See SFC's "Consultation Conclusions Concerning the Regulatory Oversight of Credit Rating Agencies", 29 October 2010 para 63

106 SFC CRA Code para 30

107 Recital 6, EU Regulation (EC) No 1060/2009

108 Anex 1, Section B EU Regulation (EC) No 1060/2009. "Credit rating activities" is defined by Article 3, 2 as meaning "data and information analysis and the evaluation, approval, issuing and review of credit ratings"

${ }^{109}$ For example, its Weekly Market Outlook publication discusses a variety of market, economic and business matters that may be relevant to credit assessment.

110 Discussed in Section 6.2
} 


\section{CONSTRUING THE RF REPORT AS A CREDIT RATING}

The Tribunal determined the RF Report to be either (1) itself a credit rating or (2) "part and parcel of Moody's ratings themselves." 111 This Section 4 discusses the former, Section 5 discusses the latter. In both sections, the considerations of Section 3 have, to the extent possible, been put aside for these purposes.

This Section 4 undertakes a detailed analysis of the more specific means by which the Tribunal has sought to identify the issuance of the RF Report as Type 10 regulated activity, as well as the specific language used by the Legislature in providing for the CRA regulatory regime. It argues, contra the Tribunal, that the scope of "credit rating" and "providing credit rating services" is in fact subject to well-defined parameters in which certain matters are to be considered to the exclusion of other considerations. It concludes that the RF Report falls short of meeting the requirements of the statutorily defined term.

Section 4.1 reviews the means by which the Tribunal has framed the RF Report as a credit rating. It is suggested that the link established by the Tribunal is tenuous at best, and appears based on an analysis that is in some ways back-tofront.

Section 4.2 clarifies the distinction between credit risk, creditworthiness and a credit rating, a distinction that appears to be at times muddled in the determination. That a report may comment on risks pertinent to creditworthiness does not suffice to render it a credit rating.

Section 4.3 comprises a more detailed examination of the defined term "credit rating". Section 4.3.1 considers the meaning of the phrase "using a defined ranking system". Section 4.3.2 considers the meaning of the phrase "primarily regarding" creditworthiness. It is argued that the Tribunal's construal of "credit rating" has not taken into account factors relevant to Legislative purpose when introducing CRA regulation that affect the nature of the RF Report. It is concluded that the RF Report falls outside the perimeter of CRA regulatory oversight.

\subsection{The Tribunal's position}

Connecting the red flag framework exclusively and particularly to an opinion on creditworthiness is not a straightforward matter. Nowhere in the RF Report does Moody's describe the red flag framework as identifying creditworthiness per se or implying an impact on their existing rating opinions. The opening paragraph of the RF Report describes the red flag framework as "highlight[ing] issues meriting scrutiny to identify possible governance or accounting risks for nonfinancial corporate issuers". The front page of the RF Report also states that the framework "can help identify areas to investigate but cannot serve as mechanisms to rank order credit risk", and that the red flags "do not represent a change in our rating methodologies."

The Tribunal's determination is less than clear precisely how that "something more" is established that causes the RF Report to be a credit rating. The Tribunal somewhat peremptorily states that "The [RF] Report is focused on, and gives opinions regarding, the credit worthiness of the corporate issuers" and goes on to cite, apparently in support, that:

"The opening sentence of the [RF] Report ... states: 'In rapidly developing emerging markets, the use of frameworks to assess elements of credit risk

${ }^{111}$ Determination para 102 
provides consistency in identifying relative strengths and weaknesses across a growing pool of rated issuers. ${ }^{\prime \prime \prime 112}$

The cited statement from the RF Report is patently somewhat generic and does not on an ordinary reading mean that the red flag framework is itself or is intended to be a credit rating system. Indeed, the next sentence of the RF Report states "In this report, we look at 20 red flags ... that highlight issues meriting scrutiny to identify possible governance or accounting risks for non-financial corporate issuers in emerging markets." An ordinary reading of that sentence also does not imply that the red flag framework, or Moody's, goes beyond assessing elements of credit risk to express a credit rating.

While the Tribunal does seek to "look at the report as a whole"113 and does consider various qualifications in the RF Report, ${ }^{114}$ the approach is influenced by other considerations. The relevance of certain extrinsic factors have been discussed in Section 3 but have been put aside for the purposes of the discussion in this section. The media and research reports cited by the Tribunal ${ }^{115}$ appear to have been referenced under a presumption that either (1) the RF Report is a credit rating, (2) they support the basis on which the RF Report is a credit rating, or (3) they are somehow otherwise relevant to its determination. If so, this would represent a back-to-front approach.

Consider the citation of the Market Watch reference to Cantor Fitzgerald's view that "markets should demand higher credit premium and lower stock valuation for companies receiving such 'red flags' in compensation for these risks." ${ }^{116}$ One can agree with the Tribunal this indicated the companies the subject of the RF Report "were now seen by the market - whatever the qualifications given by Moody's in the Report - as carrying risks that could not be ignored". ${ }^{117}$ However, that investors might read the contents of the report as relevant to credit premium logically cannot be upended into an argument that the red flag system constitutes a credit rating. A categorization based around "how many red flags" may be merely an emergent quality of the red flag framework rather than one that defines and shapes the framework into a credit rating per se. IOSCO's definition that:

"'Credit rating'... means an assessment regarding the creditworthiness of an entity or obligation, expressed using an established and defined ranking system" ${ }^{118}$

cannot be reversed into:

credit ratings are assessments of credit risk that produce a defined ranking system.

Rather, to satisfy the statutory definition of "credit rating" it is necessary that the data set be used to express an opinion. In this regard, the approach of the

\footnotetext{
112 At para 87

113 Determination para 96

114 Eg at Determination para 94 and 97

115 Market Watch, Apple Daily and Bloomberg (all dated 12 July 2011); Macquarie Equities Research note dated 13 July 2011; Wall Street Journal, edition of 24 July 2011 (see

Determination para 34, 35, 36, 39, 43)

116 Determination para 35

117 Determination para 37

118 "Code of Conduct Fundamentals for Credit Rating Agencies" IOSCO FR05/2015, March 2015, page A-4
} 
Tribunal at times appears to muddle the distinction between credit risk, creditworthiness and a credit rating, as discussed next.

\subsection{Ratings and creditworthiness distinguished}

The Tribunal noted that credit ratings refer to the risk of debt not being paid when due:

"'Credit ratings' have been described as 'opinions about relative credit risk' and 'credit risk' itself has been described as 'the potential for loss due to failure of a borrower to meet its contractual obligation to repay a debt in accordance with the agreed terms'." ${ }^{119}$

This definition, while not incorrect and useful for many purposes, glosses over the important distinction, implicit in the statutorily defined term, between (1) "creditworthiness" qua the assessment of credit risk, and (2) "credit rating" which refers only to the opinion expressed on creditworthiness.

The Tribunal's determination does not always clearly distinguish between the two in the hierarchical manner required by the legislation, resulting in some uncertainty as to the exact means by which the Tribunal connects the red flag framework exclusively and particularly to being an opinion on creditworthiness.

The Tax Court of Canada provides one of the few judicial statements of relevance:

"In general, a credit rating is a credit rating agency's opinion of the general creditworthiness of an obligor, or the creditworthiness of an obligor with respect to a particular debt security or other financial obligation, based on relevant risk factors." ${ }^{120}$

This statement is in general alignment with the definition provided by the SFO.

"Creditworthiness" is not defined by the SFO, the term only appearing once in the ordinance. It is to be distinguished from "credit rating" - they are not the same thing. The SFO describes the latter as being an opinion on the former. An opinion on creditworthiness can, if the other statutorily defined requirements are met, give rise to a credit rating. The distinction is one that is important to appreciate for the purposes of examining the Tribunal's determination and understanding the nature of the RF Report.

The approach not to define "creditworthiness" is consistent with international practice ${ }^{121}$ and suggests the word be given its ordinary meaning: "the extent to which a person, firm, etc., is considered suitable for financial credit." ${ }^{122}$ Creditworthiness thus involves a consideration of what acceptable credit risk means. The subjectivity of "acceptability" can be contrasted with other factors relevant to credit risk, such as debt-to-income ratio and collateral, which are quantifiable.

\footnotetext{
119 The Tribunal quoting the definitions provided by the Global Association of Risk Professionals - see Determination para 9

120 General Electric Capital Canada Inc. v. Canada, [2009] T.C.J. No. 489 (Tax Court appeal) at 49

${ }^{121}$ E.g. The papers issued by IOSCO do not define 'creditworthiness' nor does legislation in the EU, US, Japan, Australia or Mexico. For example, see 15 USC 78c

122 Oxford English Dictionary Third Edition 2013
} 
Credit risk is generally recognized as representing "the capacity and willingness of a debtor to meet its obligations when due."123 This involves elements of subjective judgment in the assessment of risk that goes beyond merely evaluating the relationship between an issuer's resources and financial performance and its capacity to pay. A CRA must:

"pay careful attention to ... the competences and character of its management. ... Ratings include a highly qualitative judgment about the character of the issuer, in the same way that traditional bank credit decisions did." 124

A consideration of these factors is relevant to an assessment of credit risk, and some of them are reflected in the RF Report. However, an assessment of credit risk factors does not, for the above reasons, itself amount to an opinion being expressed on creditworthiness - more is required.

When a CRA issues an opinion on creditworthiness:

"they assess the likelihood that an issuer will default either on its financial obligations generally (issuer rating) or on a particular debt or fixed income security (instrument rating)" (emphasis added). ${ }^{125}$

Expressed plainly, a credit rating is a CRA's "opinion of how likely an issuer is to repay ... a particular debt or financial obligation, or its debts generally." ${ }^{126}$

The distinction between elements of credit risk that are considered and the opinion that subsequently emerges is illustrated by the different approaches taken by the three largest CRAs - Moody's, Standard \& Poor's Financial Services ("S\&P"), and Fitch Ratings ("Fitch"). All of them "agree that a credit rating is an opinion about whether the issuer of a fixed income security will pay amounts due on time and in full [...and] that ratings ... place an issuer or an instrument on a scale from least likely to default to most likely to default". ${ }^{127}$ While each of these CRAs might engage in highly similar tasks and considerations as regards an assessment of credit risk, ${ }^{128}$ the formation of the opinion is subject to an additional process that is somewhat unique to each. Moreover, the opinions once

\footnotetext{
${ }^{123}$ Q Liiu, P Lejot and DW Arner, "Finance in Asia" Routledge 2013, page 217

124 Herwig M. Langohr and Patricia T. Langohr, "The Rating Agencies and their Credit Ratings: What They Are, How They Work and Why They Are Relevant", 2008 John Wiley \& Sons Ltd, page 31

${ }^{125}$ Commission of the European Communities, 2005, Communication from the Commission on credit rating agencies, December 23, 2005/11990, 1-9, page 2

${ }^{126}$ Report On The Activities of Credit Rating Agencies, IOSCO, September 2003, Statement of the Technical Committee of IOSCO September 2003

127 Herwig M. Langohr and Patricia T. Langohr, "The Rating Agencies and their Credit Ratings: What They Are, How They Work and Why They Are Relevant", 2008 John Wiley \& Sons Ltd, page 24

${ }^{128}$ However, even at this level practices vary between different CRAs, with potentially significant consequences. For example, the concept of 'default', commonly understood as a failure to pay or to meet an obligation (Oxford English Dictionary) is given more specific meanings. Moody's regards it is an

"event that changes the relationship between the bondholder and the bond issuer from the relationship that was originally contracted, and subjects the bondholder to an economic loss.' (See Cantor, R., Hamilton, D.T, Ou, S., and Varma, P., 2005, Default and recovery rates of corporate bond issuers, 1920-2004, Special Comment: Moody's Investors Service, January, Report 91233, 1-40, page 39.) .This can give rise to a wide range of extracorporate circumstances becoming relevant. "Default" can also be regarded as a purely technical term taken from debt or similar contracts that means certain specific occurrences which may have consequences in terms of creditor rights
} 
formed "generally correspond to probability of default treatments under the [relevant CRA's] standardised approach[es]". ${ }^{129}$

Placing these considerations against the RF Report, it is clear that the red flags cover elements relevant to credit risk assessment. For example, quality of cash flow generation and deviations in working capital. The issues covered in understanding the companies reviewed also go beyond matters pertaining only to credit - the same issues are also of interest to equity investors.

Each flag clearly is not an opinion on creditworthiness. They operate in a simple binary manner. Either the specific criterion is met and a red flag raised, or it is not and no flag is raised. This reflects the fundamental distinction between elements that might be pertinent to forming an assessment of creditworthiness, and a rating of creditworthiness that might or might not emerge from those elements.

The red flags are also part of a framework. The RF Report itself makes a generic reference to "the use of frameworks to assess elements of credit risk" ${ }^{130}$ There is no dispute that more red flags amounts to more risk issues along the particular dimensions of risk addressed. So is Moody's thereby expressing an opinion primarily concerned with creditworthiness using that framework? In other words, are the particulars of the statutory definition of "credit rating" satisfied? In the remainder of this Section and in Section 5 it is argued that it is not and that the RF Report is more sensibly regarded as a derivative report compiled for promotional purposes.

\subsection{Construing 'credit rating'}

The purposive approach as undertaken by the Tribunal (reviewed in Section 3) gave scant attention to the interpretation of the "credit rating" definition, the elements comprising the term, and the grammatical relationship between those elements. The Tribunal's assessment of the term was as follows:

"the phrase 'credit ratings' is broadly defined. The Legislature has not condescended to specific accountancy directives or mathematical formulae.. ... It allows for different forms of credit ratings in respect of a range of subject matters. ... [and] is broadly drafted so as to meet the exigencies of changing circumstances" ${ }^{131}$

..."Understandably, therefore, the [SFO] defines 'credit ratings' as 'opinions', that is, as views, judgments or beliefs, without any limitation to their form other than that they are 'expressed' using a 'defined rankings system', namely, a system that divides its subject matter into ranks or classes that are clearly specified" ${ }^{132}$

...[a defined ranking system] "may come in many forms; it may be selfcontained or it may be complementary to an existing system." ${ }^{133}$

"it is also significant that the statutory definition does not limit the factors that may be taken into account in any such assessment [of debt obligations]" 134

\footnotetext{
129 BASEL IOSCO JOINT FORUM Page 4

${ }^{130}$ RF Report page 1

131 Determination para 81

132 Determination para 83

133 Determination para 84
} 
There is no doubt that the definition of "credit rating" is not concerned with the precise methodology involved in producing a rating. Under Hong Kong's regulatory architecture, statute only concerns itself with the output of a rating process - does an item of information constitute a credit rating or not? Conduct aspects of the ratings process, including matters pertaining to methodology, are instead governed by non-statutory regulations, namely, the SFC CRA Code. ${ }^{135}$ The non-statutory requirements remain specific notwithstanding that they also do not concern themselves with accounting directives or mathematical formulae.

In Sections 4.3.1 and 4.3.2 it is argued that the Tribunal's brief assessment of "credit rating" has led to a misconstruction of it's meaning both on an ordinary reading and having regard to the accepted practices of CRAs.

\subsubsection{Meaning of 'using a defined ranking system'}

To be a "credit rating" an opinion must be "expressed using a defined ranking system" (emphasis added). That is, the opinion expressed and the system used are related but nevertheless distinct. It would not be enough that the red flag framework was merely "a system that assessed elements of credit risk by a form of ranking. ${ }^{\prime \prime 36}$

In Bathurst Regional Council v Local Government Financial Services Pty Ltd, ${ }^{137}$ the Court noted the CRA in that case had "published a system of stand alone ratings where the relevant information for an investor was contained in the rating itself and the accompanying definition [the CRA] assigned to the rating." ${ }^{138}$ That is to say the ranking system is the defined scale of $A A A, A A$, etc. - it is not comprised in the CRA's methodology, nor in any allocation of "markers" (such as red flags) that might be relevant to the CRA's methodology. These distinctions, between the methodology, the ranking system, and the opinion expressed, also mean that once a rating has been given it "is not dependent on [the CRA's] explanation of how it reached the rating." ${ }^{\prime 139}$

Unlike the opinion, which must concern creditworthiness, the phrase "defined ranking system" does not on a straightforward reading appear to mean that the system must rank creditworthiness per se. The SFC implicitly recognized this in their first consultation, noting that broker recommendations using a "'buy, 'hold' or 'sell'" is capable of being a defined ranking system. ${ }^{140}$ However, a reading of the phrase "defined ranking system" is arguably going to be blinkered if the preceding transitive verb "using" is ignored.

According to common practices of the CRA industry, defined ranking systems are very often designed as an ordinal scale (although they might also come in other forms such as market credit spreads and market-implied credit ratings). ${ }^{141}$ It is

\footnotetext{
134 Determination para 86

135 Hong Kong's architecture in this regard is distinct from EU Regulation (EC) No $1060 / 2009$ which itself deals with both the output and certain conduct matters in relation to its production (such as avoidance of conflicts of interest)

${ }^{136}$ Determination para 96

137 (No 5) [2012] FCA 1200 (Federal Court of Australia)

138 Ibid. at 1465

${ }^{139}$ Ibid. at 1464

${ }^{140}$ SFC's "Consultation Paper Concerning the Regulatory Oversight of Credit Rating Agencies", 19 July 2010, para 16

${ }^{141}$ See Herwig M. Langohr and Patricia T. Langohr, "The Rating Agencies and their Credit Ratings: What They Are, How They Work and Why They Are Relevant", 2008 John Wiley \& Sons Ltd page 43
} 
hard to conceive how an opinion on creditworthiness under any ranking system can be expressed by using a system that is not sensitive to credit risk. One might put this another way: a ranking system that does not bear a statistically significant correlation with creditworthiness is likely to be of little use, if any, to forming and expressing an opinion on creditworthiness. Indeed, as Moody's point out when introducing their red flag framework on page 1 of the RF Report, the correlation between the number of flags and creditworthiness is "limited" - some groupings of companies revealing a "lack of correlation", others showing a "degree of correlation". ${ }^{142}$ According to Moody's, this shows that "screens for governance or accounting risks [i.e. the red flag framework] can help identify areas to investigate but cannot serve as mechanisms to rank order credit risk."143 That statement means the red flag framework cannot be employed as an ordinal system.

The Tribunal interprets the non-correlation in a different manner, stating that it goes to the limitations of the framework but "does not go to the issue of whether a credit rating system... was presented in the report". ${ }^{144}$ This presents a chickenand-egg conundrum and it is suggested that the Tribunal's view must overcome the following five considerations that appear not well explored in its determination.

First, the Tribunal appears to have come to its conclusion not through an isolated examination of the RF Report but via a review of various surrounding circumstances including the internal processes, intentions and expectations leading to the preparation and publication of the report, in particular, the discussions surrounding initial expectations and subsequent research findings. For reasons discussed in Section 3.2, this would appear to be a line of reasoning that lies outside the scope of Legislative intent.

Second, as to whether a non-correlation goes to the limitation or the nature of the system, one needs to possess a basic appreciation of correlative statistics as a research tool in the social sciences. What is the import of the Tribunal citing the unexpected nature of the finding? That Moody's may have originally anticipated the red flag framework would align with its opinions of creditworthiness reflects a reality of research endeavours: dealing with unexpected results is hardly abnormal and frequently informative. To describe this as implying that the framework is confused ${ }^{145}$ fails to recognize that reality. ${ }^{146}$ Rather, the statistic, if correctly calculated and disclosed (as appears to be the case), is simply something to be interpreted by the reader according to its own purposes. ${ }^{147}$

\footnotetext{
142 RF Report page 4

143 RF Report page 1

144 Determination para 97

145 Per the SFC at Determination para 148

146 While the Tribunal refer to various internal communications to assert a case of confusion and disagreement, the reality is that the exchange of differing views is a normal and healthy part of an organization and a research endeavour, and that such exchanges should not be subject to interpretation via a rear view mirror, or in any way suppressed (for example, for fear that a court might later reinterpret views).

${ }^{147}$ In a similar vein, the phrase "outlier" is a standard statistical term used to describe observations that depart materially from the bulk of a population of observations, the word "negative" merely indicating the directionality of the divergence. Accordingly, to describe the term "negative outlier" as "pejorative" is a failure to recognize the common language of statistics. However, Moody's here departs from the statistical use of the term, apparently applying it on a selective and unexplained basis - many companies that triggered the same number of red flags as the "negative outliers" were not identified as such. This departure is likely to be of relevance to the question of whether the RF Report was misleading.
} 
Third, Moody's discussion of the non-correlation may serve as a means of distinguishing the red flag framework from Moody's traditional credit ratings. The front page of the RF Report states "These findings ... cannot serve as mechanisms to rank order credit risk." ${ }^{148}$ On a plain reading that language distinguishes the red flag framework from its traditional credit ratings, which are, by contrast, pointedly arranged as ratings of credit risk within an ordinal system. The Tribunal's reading of those words is anything but plain.

Fourth, it needs to deal with the perimeter of where a framework is so materially limited as regards credit risk that it is not possible to express an opinion on creditworthiness, but merely hold oneself out as doing so. Since the SFC has previously identified "buy/sell/hold" as a defined ranking system, one might ask whether it can be used to express an opinion on creditworthiness. If a broker were to give such an opinion - e.g. "Based on our latest research report which has changed our 'buy' to a 'sell' recommendation, my opinion is that the company's creditworthiness is trending down" - would this or could this be regarded as a credit rating? That it should not is at least consistent with the position of the SFC that "Advising on securities may include providing opinions on a company's creditworthiness, but only as a factor impacting upon advice on whether ... securities [i.e. equity or debt] should be acquired or disposed of. ${ }^{\prime 149}$ It would not be a surprising conclusion, nor one that is inconsistent with the purposes of regulating CRAs, that the definition of credit rating implies or requires that the ranking system on which an opinion is based must somehow be capable of being used for ranking creditworthiness - that it be designed or targeted to measure credit risk, not merely some broader range of concerns of which creditworthiness may or may not be but one consideration. ${ }^{150}$ Section 6.1 below discusses the ramifications of drawing the definition of credit rating too widely.

Fifth, it requires the nature of the RF Report to be established as an opinion "primarily regarding" creditworthiness.

\subsubsection{Meaning of 'primarily regarding'}

There is not, quite surprisingly, any discussion in the Tribunal's determination of the import of these two words in the definition. The phrase does not appear to be used in any other statute of Hong Kong, nor subject to prior judicial interpretation. ${ }^{151}$ Given the international context of introducing CRA regulation in Hong Kong, it is also of interest to note that neither the U.S. or the EU legislation, nor IOSCO's Code of Conduct Fundamentals for Credit Rating Agencies incorporates such a requirement. ${ }^{152}$

\footnotetext{
148 RF Report page 1

149 SFC's "Consultation Paper Concerning the Regulatory Oversight of Credit Rating Agencies", 19 July 2010, para 16

150 EU Regulation (EC) No 1060/2009 avoids the "buy/sell/hold" problem by specifically providing, in Article Article 3, 2(b), that such recommendations shall not be considered credit ratings

${ }^{151}$ Search conducted for the phrase "primarily regarding" on the database of the Hong Kong Legal Information Institute, July 2016

152 s3(a)(60) of the Exchange Act provides "The term 'credit rating' means an assessment of the creditworthiness of an obligor as an entity or with respect to specific securities or money market instruments. 15 USC 78c (a)(60) provides "The term 'credit rating' means an assessment of the creditworthiness of an obligor as an entity or with respect to specific securities or money market instruments." The EU defines it as "an opinion regarding the creditworthiness of an entity [etc.]". The IOSCO Code provides "'Credit rating' or 'rating' means an assessment regarding the creditworthiness of an entity or obligation, expressed using an established and defined ranking system."
} 
The natural language use of the phrase suggests the Legislature intended to distinguish between reports predominantly concerned with an evaluation of creditworthiness, and reports that are not. However, the presence and plain meaning of these additional words cannot simply be ignored. ${ }^{153}$

The Legislature might have wanted to include these additional words this as part of the need to establish, as the Tribunal noted, a bright line between regulated and non-regulated activities, or between credit ratings from research reports that contain elements relevant to credit risk. ${ }^{154}$ There is obviously an enormous volume of published materials discussing the shortcomings of corporates that may be relevant to assessments of creditworthiness but which are typically not considered to be discussions of risk of default. They are instead characterized as, for example, research reports, or perhaps discussions of corporate sustainability. Default may be a potential consequence of bad risk governance, but a discussion of bad risk governance, even if based around a ranking system, does not necessarily amount to an assessment of the risk of default. The SFC itself uses indicators such as "companies with history of losses, frequent corporate restructuring, changes of auditors" to assess corporate risk and to "identify red flags". ${ }^{155}$ These regulatory concerns are confluent with the interests of investors generally. It follows that the concerns of the RF Report - governance and accounting risks, which are matters equally of interest to equity investors - does not of in and of itself render the discussion primarily regarding creditworthiness. As already noted, it is not sufficient that a credit-related usage might emerge from the RF Report. Something more is required.

With these distinctions in mind, the perimeter of the phrase 'primarily regarding" can be considered.

\section{That which clearly falls within the perimeter}

As already discussed in Section 4.2, credit ratings (such as those traditionally issued by Moody's under their usual ratings classifications ${ }^{156}$ ) are not themselves the creditworthiness - the credit rating, being an opinion on creditworthiness, points to creditworthiness. The rating is the signifier, the creditworthiness the signified. The rating is typically expressed as being one of a set of ranked symbols or icons used by the CRA. The issuer of the rating seeks to facilitate a shared or common understanding of what meaning each rating rank is intended to convey by providing a specific definition of each rating. Such statements are not only long standing industry practice but are also required by regulations. ${ }^{157}$ To illustrate by way of example, one might look at the definitions used in Moody's baseline credit assessments ("BCAs") of corporates being "opinions of issuers' standalone intrinsic strength, absent any extraordinary support from an affiliate or a government" so, for example, a BCA rating of 'aaa' means:

\footnotetext{
153 See Lord Millett NPJ in China Field Ltd $v$ Appeal Tribunal (Buildings) [2009] HKCFA 95; [2009] 5 HKLRD 662; (2009) 12 HKCFAR 342; [2009] 5 HKC 231; FACV 2/2009 (30 October 2009) at 36

154 Determination para 206

155 Carlson Tong, SFC's Chairman, in a speech titled "Towards better corporate governance" at the Chamber of Hong Kong Listed Companies 11th anniversary gala dinner, 12 December 2013. The full speech is available at http://www.sfc.hk/web/EN/files/ER/PDF/Speeches/Carlson\%2020131212.pdf ${ }^{156}$ See generally "Rating symbols an definitions", Moody's Investors Service, May 2016 ${ }^{157}$ For example, para 54 of the SFC CRA Code requires a CRA to "clearly define a given rating symbol and apply it in a consistent manner"
} 
"Issuers assessed aaa are judged to have the highest intrinsic, or standalone, financial strength, and thus subject to the lowest level of credit risk absent any possibility of extraordinary support from an affiliate or a government"

whereas a rating of caa means:

"Issuers assessed caa are judged to have speculative intrinsic, or standalone, financial strength, and are subject to very high credit risk absent any possibility of extraordinary support from an affiliate or a government. ${ }^{158}$

The uses to which a particular rating is put will vary according to each user's needs whether lender, investor or regulatory body. Equity investors may also choose to use them. However, different potential usages do not change the intended relationship between the specific credit rating issued and creditworthiness, nor the breadth of the rating's intended meaning.

In short, credit ratings, by their nature and as normally understood, do not signify a broad, and possibly ill-defined, range of other potential meanings. They are quite specific.

\section{That which is not primarily regarding creditworthiness}

General opinions and views on equity or other matters concerning the company not addressing creditworthiness clearly fall outside the perimeter.

As a negative definition ("not primarily"), the scope of the matters that fall outside the perimeter are wider than what falls within it. Many things are potentially covered. Reports appraising a range of corporate issues, some of which might also be of interest to a person interested in the question of creditworthiness, would need to be regarded as falling outside this perimeter if creditworthiness was not its primary focus.

Categories defined negatively are by their nature perilous to define. However, an application of the law to the RF Report does not require this to be done. Rather, it requires a case to be proven that the report falls within the perimeter of "primarily regarding".

The Tribunal has considered a number of surrounding circumstances to suggest that Moody's primary focus in preparing the report was driven by and ultimately pertained to its interest, as a CRA, in creditworthiness. This conclusion in itself seems not untrue. ${ }^{159}$

Bearing in mind the nature of the relationship between rating as signifier and creditworthiness as signified, another way of addressing the question of primacy is to ask whether a report is capable of giving rise to this relationship. Although credit ratings may have a different information value to different users of them, ${ }^{160}$ it nevertheless seems impossible to say that a report is primarily

158 "Rating symbols an definitions", Moody's Investors Service, May 2016, page 29-30

${ }^{159}$ Section 3.2 above argued that surrounding circumstances are not legally determinative of the nature of the report itself. Rather, the RF Report must be considered plainly and directly.

${ }^{160}$ DW Arner et al, "Regulating Credit Rating Agencies in Hong Kong: Lessons from the Global Financial Crisis" Banking \& Finance Law Review 25.3 (Jun 2010), 361-403, page 364 
concerned with creditworthiness if nothing in the report clearly points to creditworthiness, i.e., if there is an absence of the signifier-signified relationship.

The red flag framework, to operate as a signifier of creditworthiness, should be capable of giving rise to a common understanding of what a particular number of red flags assigned to a company means in terms of its creditworthiness. For example, it should make sense to ask "What is the credit rating of company $X$ and $Y$ in the RF Report?", and a commonly understood answer pertaining to creditworthiness capable of being given. It is not clear from the Tribunal's determination whether evidence was gathered on this question. Some scant and inconclusive evidence from the media and one research report is cited. ${ }^{161}$

The Tribunal's own view was that "a company allocated 20 red flags represented, on any ordinary reading, the maximum potential credit risk; a company allocated none at all represented the minimum potential credit risk" (emphasis added). ${ }^{162}$ This implicitly assumes ordinality in the way the scale works.

However, an accurate answer to the question asked above might be: " $X$ has seven red flags and $Y$ has only five". Such an answer does not provide an indication of the opinion on creditworthiness of $X$ or $Y$, nor is it capable of indicating an opinion on the comparative creditworthiness of $X$ or $Y$ - not least since, as Moody's states in the RF Report, all flags are not equally weighted. ${ }^{163}$ For this reason, an alternative answer to the question such as " $X$ is less creditworthy that $Y$ because $X$ has more red flags than $Y$ " is also not sensible to give - the ordinality required to enable one to do so is lacking. ${ }^{164}$ An accurate answer to the question would therefore appear to fall well short of the basic requirement that a credit rating should, in the words of the U.S. Securities and Exchange Commission, "be a credible assessment of the relative creditworthiness of an obligor or obligation." 165

To the extent different users may interpret ${ }^{166}$ the total number of red flags as meaning different things, there is no common understanding of the framework capable of giving rise to the relationship of signifier (the rating) and signified (creditworthiness). The relationship discussed above, wherein a rating points to creditworthiness via an opinion or assessment that has been expressed in the rating, fails to form. To assert that the red flag framework primarily points to creditworthiness assumes a defined rating system that does not appear to be supported by the facts of the RF Report.

\footnotetext{
161 Market Watch, an industry focused website operated by Dow Jones, in paras 34-35; Apple Daily, a Hong Kong newspaper, in para 36; Wall Street Journal, in para 43. The research report is from Macquarie Equities Research, at para 43

162 Determination para 29

${ }^{163}$ RF Report page 3, first new para

164 "Ordinality implies that all ratings along [an ordinal credit rating] scale are comparable." See Herwig M. Langohr and Patricia T. Langohr, "The Rating Agencies and their Credit Ratings: What They Are, How They Work and Why They Are Relevant", 2008 John Wiley \& Sons Ltd, page 43

${ }^{165}$ U.S. Securities and Exchange Commission Release No. 34-72936; File No. S7-18-11 dated 10/14/14, page 436. This document adopts various amendments pursuant to Title IX, Subtitle C of the Dodd-Frank Wall Street Reform and Consumer Protection Act concerning "Improvements to the Regulation of Credit Rating Agencies" amongst other things

${ }^{166}$ I.e. and not merely use the framework for different purposes
} 


\section{A deficient rating?}

The counterargument, reflecting the position of the SFC and the Tribunal, is that the failure of the RF Report to provide definitions, detailed methodologies and so on to amount to a credible assessment, does not operate to make it not a credit rating but instead serves to make it one that is deficient. Accordingly, it fails to meet the standards and requirements of the SFC's codes.

In this vein the Tribunal suggested that "educated readers ... would have treated the red flag framework as a 'screen' to enable them to be given extra insight into Moody's established systems" in the sense of it being "used to fine tune Moody's credit ratings". ${ }^{167}$ Such an understanding ignores the observation made in the Bathurst ${ }^{168}$ case that a rating once given is not dependent on a CRA's subsequent explanation of how it reached the rating, may be overly simplistic, highly presumptive of the approach of an educated reader, and difficult to establish. The Tribunal itself identifies one publication that recognizes the distinction that "the warnings were short of credit downgrades"169 and a number of market commentators have expressed surprise or dismay that the RF Report has been regarded as a credit rating.

The RF Report: (1) expressly points out, as already discussed, that the correlation between the red flags and existing credit ratings of creditworthiness is limited; (2) accordingly does not provide any definitions, for example, that a certain number of flags means such-and-such as regards creditworthiness - there would be no sense in doing so given the lack of correlation; (3) states that a corporate's "tripping of many red flags does not represent an immediate rating concern"170 and (4) indicates that although flags operate rather generically as "warning

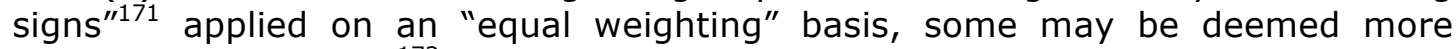
important than others ${ }^{172}$ - i.e. all red flags are not equal. An example of the latter is Moody's discussion of a red flag triggered as a result of a CEO's change of position which Moody's regards as "positive because it split the role of chairman and $\mathrm{CEO}^{\prime \prime}{ }^{173}$

If, notwithstanding the foregoing, one imagines that a lay person or ill-informed reader looks at the red flags as a simple counter of governance and accounting risks that reveals creditworthiness of a particular issuer, e.g. that an issuer with five flags is more creditworthy than one with seven, it should be noted that the Tribunal is not obligated to adopt the same non sequitur.

\subsection{Conclusions on the construal of "credit rating"}

The Tribunal's broad-brush approach to the meaning of "credit rating" glosses over important differences between elements that pertain to, inter alia, credit risk and the opinion that is expressed on creditworthiness. It may also be at odds with the approach taken in the SFC CRA Code, the overall tenor of which appears to regard credit ratings as something specific.

\footnotetext{
167 Determination para 162

168 Bathurst Regional Council v Local Government Financial Services Pty Ltd (No 5) [2012] FCA 1200 op. cit.

169 Market Watch, 12 July 2011, as cited in Determination para 34. However, the Tribunal goes on to conflate the subsequent Market Watch comments as being pertinent to a consideration of the nature of the RF Report, as discussed in Section 4.1 above.

170 RF Report page 4

${ }^{171}$ RF Report page 2

172 RF Report page 3, first new para

${ }^{173}$ RF Report page 5, in the discussion of West China Cement
} 
For the reasons set out above and in Section 3, that approach is intimately tied up with what appears to be the wrong starting point for the analysis of the RF Report leading to what is effectively an inverted analysis of the issuance and nature of the RF Report.

The terms reviewed in Section 4.3 above do carry specific meanings that reflect these distinctions and the practices of the CRA industry, and serve to keep distinct the rating products of CRAs from other information-providing functionalities in the market.

It is therefore suggested that Moody's description of the framework as "an interesting screen to identify potential areas of concern for follow up and closer scrutiny"174 is more consistent with the RF Report falling outside the tight perimeter of "primarily regarding". It is well capable of signifying a range of concerns of which creditworthiness is just one.

However, there is one more approach taken by the Tribunal that has not been attended to in within the specific focus of this Section and which requires consideration: the argument that the RF Report supplements or amplifies Moody's traditional credit ratings, and that by doing so it promotes the information value of those ratings (although which particular ratings is not made clear by the Tribunal) and consequently the usefulness of Moody's ratings to the users thereof. As such, the RF Report becomes part of Moody's existing credit ratings. That argument is discussed in Section 5.

\section{CONSTRUING THE RF REPORT AS PART AND PARCEL OF MOODY'S OTHER CREDIT RATINGS}

The Tribunal's alternative determination that the RF Report is "part and parcel of Moody's ratings themselves" ${ }^{\prime 175}$ relies in large part on Moody's press release, in particular the use of the word "supplemental" therein (the concerns over using the press release in the analysis of the RF Report have already been discussed in Section 3.2.3). The press release states that: ${ }^{176}$

"The [red flag] framework is supplemental to Moody's methodological approach to rating non-financial corporates in the emerging markets, and is aimed at highlighting discreet risks that may warrant further investigation" (emphasis added).

The Tribunal cites the press release as important to the link between the RF Report and Type 10 regulated activity:

"Moody's accepted... although there was a link... there being no exact correlation... the red flag system had to be something more than a mere illustration of Moody's existing ratings. As the press release announced, the red flags were 'supplemental' to Moody's existing ratings: adding to them and/or amplifying them." ${ }^{177}$

\footnotetext{
174 RF Report page 2

175 Determination para 102

176 The press release can be found at Moody's web site.

https://www.moodys.com/research/Moodys-Accounting-and-governance-warning-signsfor-emerging-market-companies--PR_222323

177 Determination para 32. The reference to the statement on page 4 of the RF Report: "An issuer's tripping of many red flags does not represent an immediate rating concern because our ratings already reflect many of the issues highlighted by the relevant red flags, and the ratings also incorporate more than just the potential concerns that the flags
} 
The reference to the RF Report being "supplemental" is used only once in the press release and not at all in the RF Report. Nevertheless, the Tribunal gives the word considerable attention ${ }^{178}$ as part of its argument that the RF Report is intended to amplify and becomes part of Moody's credit ratings.

\section{1 "Supplemental to"}

The meaning of the phrase "supplemental to" is reasonably straightforward - it is something that forms or serves as a supplement, i.e. a thing:

"added to make good a deficiency or as an enhancement; an addition or continuation to remedy or compensate for inadequacies; ... [a] part added to complete or extend a literary work or any written account or document". ${ }^{179}$

The Tribunal appears to have read "supplemental" (1) against Moody's existing credit ratings, and in a (2) negative or (3) transformational manner. None of these readings seem warranted, as explained below.

\subsubsection{The subject is methodology}

Although the press release states it is Moody's "methodological approach to rating" that is being supplemented, the Tribunal instead reads the statement as supplemental to Moody's credit ratings:

"As the press release announced, the red flags were "supplemental" to Moody's existing ratings: adding to them and/or amplifying them."180

This is a plain misreading of the press release that again reflects a failure on the part of the Tribunal to recognize important distinctions, well recognized in the CRA industry, between credit risk, creditworthiness, and credit ratings (discussed in Section 4.2). As already noted in Section 4.3.1, methodology, the ranking system, and the opinion expressed are separate and distinct matters. Methodology is merely an intermediate matter, a set of established tasks applied to credit risk factors. Methodology and any discussion of it clearly is not a rating opinion, and neither can it be an explanation or qualification of any rating decision that previously made. In brief, a discussion that references methodology is not thereby a discussion of a rating opinion. Again referencing the Bathurst case, a rating "is not dependent on [a CRA's] explanation of how it reached the rating" because "the relevant information for an investor [is] contained in the rating itself and the accompanying definition [the CRA] assigned to the rating." ${ }^{181}$

\subsubsection{Negative reading}

The Tribunal refers to 'supplemental' as implying the RF Report is "amplifying"182 Moody's credit ratings. To amplify is to enhance, enlarge, or expatiate. This seems, in the view of the Tribunal, to be necessitated by changing market

capture. Moreover, as indicated, there is only limited correlation between lower ratings and a higher number of red flags tripped."

178 Determination paras 21, 32, 82, 102, 103, 146, 147, 148, 159, 161, 164 and 192

179 Oxford English Dictionary Third Edition June 2012

180 Determination para 32

${ }^{181}$ Bathurst Regional Council v Local Government Financial Services Pty Ltd (No 5) [2012] FCA 1200 (Federal Court of Australia) at 1464 and 1465

182 Determination para 32 
conditions that require credit ratings "to be clarified, supplemented or made subject to change." 183

While one can agree with the general statement that ratings are subject to change over time, it is a significant and unfounded leap to suggest that the RF Report serves this purpose and that (by implication) without it, Moody's existing ratings would be somehow deficient or possibly in need of clarification. Moody's has well-established means, presumably consistent with the SFC's codes, to update and revise its published ratings when necessary to do so. Those means are quite distinct from the tenor of the RF Report and are clearly identified as updates to credit ratings.

It remains unclear on what basis the Tribunal has chosen to lend "supplemental to" the meaning it has, when other meanings are available. The Sunday newspaper that comes with a "Sunday Supplement" does not imply that the news in the main part of the paper is itself deficient or in need of clarification. It merely puts more information on the breakfast table, though one expects to read more about cultural interests than the latest views on Brexit.

The SFC itself provides an example of a usage that does not imply any negative implication of deficiency in the thing being supplemented. The SFC CRA Code states that it "supplements, and should be read in conjunction with"184 the SFC General Code. This reflects the fact that the two codes serve different purposes, the former dealing with matters not addressed in the latter code. The SFC's guidance to read one in conjunction with the other is of course additional to the word "supplement". Similarly, the SFO and other ordinances in Hong Kong make generous use of the word 'supplement' in a purely additive sense to provide for supplemental orders, provisions, regulations and other arrangements that imply no shortcoming in the underlying ordinance.

Moody's existing credit ratings have at no time been called into question (by the Tribunal or others) as to their sufficiency for the purposes they serve. Accordingly, in view of the foregoing considerations, any negative reading of "supplemental to" would appear to be spurious.

\subsubsection{Transformational reading}

For one thing to be supplemental to another thing also does not render it the same as that which it is supplementing. The Tribunal states that:

"it is evident that [the red flag framework] was intended to be read as amplifying and supplementing Moody's ratings, as being so intimately attendant upon them that it constituted more than mere comment and became part and parcel of Moody's ratings themselves" (emphasis added). ${ }^{185}$

"If readers were to understand the red flag framework to be supplemental, it would follow that they were effectively being provided with analysis in some respects at least additional to Moody's existing ratings" (emphasis added). ${ }^{186}$

183 Determination para 82

184 SFC CRA Code, para 2

185 Determination para 102

186 Determination para 147 
As per the example already provided under Section 5.1.2 above, the SFC's usage does not make the SFC CRA Code part and parcel of the SFC General Code. Each continues to serve its own particular purposes, and each possesses an area of mutual concern in which they overlap.

To illustrate the foregoing it is useful to give an example:

(A) "Dan's biometric measuring system of Jack indicates he is $180 \mathrm{~cm}$ tall and weights 120 kilograms giving him a body mass index of around 34 . According to Dan's defined ranking system, which is based on criteria provided by the World Health Organization, this means that Jack is obese."

Dan subsequently supplements her data with two additional facts:

(B) "Jack is from Mississippi. Jack is a Christian."

That Jack is from Mississippi and a Christian clearly does not make those matters part of Dan's biometric system, nor does it affect her defined ranking system. There is nevertheless a relevance of Jack coming from Mississippi: it has one of the highest rates of obesity in the U.S. On the other hand, that Jack is a Christian is a fact that might have some correlation with the prevailing religious beliefs in Mississippi but possibly limited correlation with obesity rates.

Dan's supplemental data in (B), and the attendant correlations and noncorrelations of course do not make the biometrician's data in (A) wrong, deficient or confused in any way. They supplement it with additional information that may be of interest to readers of Dan's biometric reports for a variety of reasons. However, they do not change or become 'part and parcel' of Dan's biometric system.

Ill-informed users of Dan's data set (i.e. (A) and (B)) may of course come to erroneous conclusions based on a poor understanding of statistics, a problem that is not an uncommon one. ${ }^{187}$

\subsection{An alternative interpretation}

Expressed plainly, the argument presented above means that one can say something extra about existing information to supplement it, but it does not follow that the something extra is the same in nature as the information it is supplementing or that it changes the existing information in any way.

The debt-oriented leaning of both the RF Report and the press release are consistent with a commercial entity that wishes to highlight matters of potential interest to its primary client base. CRAs often issue unsolicited materials to improve the market coverage of the ratings ${ }^{188}$ without such materials thereby being regarded as credit ratings (see the discussion in Section 3.3).

The RF Report noted investor concerns over the discussion in the U.S. of "potential problems with the quality of financial reporting from publicly listed

\footnotetext{
${ }^{187}$ As extensivley illustrated in Steven Levitt and Stephen J. Dubner "Freakonomics: A Rogue Economist Explores the Hidden Side of Everything." 2005 William Morrow/Harper Collins 2005

188 A Duff and S Einig "Credit rating agencies: meeting the needs of the market?", The Institute of Chartered Accountants of Scotland, 2007, page 14
} 
Chinese companies". ${ }^{189}$ Accounting risks, a matter of concern to a wide group of persons, was an important subject of the RF Report.

Indeed, the opening sentences of Moody's press release reflects the foregoing:

"Moody's Investors Service highlights, in a new report, governance and accounting risks prevalent when investing in fixed-income securities in the emerging markets. ... the 20-point framework is applied to Chinese nonfinancial corporates, wherein recent credit events have seriously destabilized investor appetite for paper in this market. ${ }^{190}$

That Moody's may have wanted to specifically position the report in a creditrelated space is consistent with the desire of a for-profit organization to engage with its clients by generating discussion and interaction (the RF Report is a paidfor report). Investors tend to see ratings as indicators of internal risk management, an issue of importance to them. ${ }^{191}$ A CRA also typically considers factors relevant to internal risk management (such as corporate governance and accounting issues) as a factor in its rating methodology. However, as discussed in Section 4.2, a report that discusses internal risk management - useful to a CRA's client base - does not of itself give rise to a credit rating.

Moody's positioning of the RF Report is also consistent with its desire to "create value for all users of our credit ratings" and to "prioritize ... transparency thought leadership." ${ }^{192}$ However, as with the other extrinsic factors discussed in Section 3, these considerations are circumstantial in nature and are not determinative of the nature of the RF Report for the purposes of the SFO.

\section{MEeTING POLICY OBJECTIVES}

As already noted, the interpretation of legislative intent is based primarily on the language used in the legislation and having regard to the public policy intent of the legislation. An interpretation of the legislation which stymies that purpose ${ }^{193}$ would prima facie be in error, particularly if other valid interpretations, or solutions to an alleged wrongdoing, are available. The same may be said of an interpretation that is inconsistent with the regulatory objectives of the legislation and its statutory regulator or Hong Kong's Basic Law. ${ }^{194}$

Whereas Sections 3 to 5 queried the syntax of the Tribunal's argument and its approach to statutory interpretation, the following sections suggest that the determination may also be interrogated as to whether it is counterproductive to the policy intent of the Legislature.

\footnotetext{
${ }^{189}$ RF Report page 2

190 Press release dated 11 July 2011, the same date as the RF Report

191 A Duff and S Einig "Credit rating agencies: meeting the needs of the market?", The Institute of Chartered Accountants of Scotland, 2007, page 35-36

192 See Moody's Annual Report 2015, page 4

193 The context of introducing CRA regulatory oversight in Hong Kong has already been discussed - see Section 1.2 above

${ }^{194}$ While Section 4 of the SFO sets out the regulatory objectives of the SFC, Article 109 of the Basic Law states: "The Government of the Hong Kong Special Administrative Region shall provide an appropriate economic and legal environment for the maintenance of the status of Hong Kong as an international financial centre." This is reflected in Section $6(2)(a)$ of the SFO which requires the SFC, in pursuing its objectives and functions, to have regard to "the international character of the securities and futures industry and the desirability of maintaining the status of Hong Kong as a competitive international financial centre".
} 
Section 6.1 considers the potential issues that could arise domestically and internationally should the Court of Appeal uphold the Tribunal's determination. Section 6.2 reviews the other provisions of the SFO relevant to the question of the legislation meeting legislative intent.

\subsection{Ramifications of the determination}

\subsubsection{Local implications}

The determination presents four main issues the market would need to grapple with.

First, the perimeter of what constitutes Type 10 regulated activity becomes less clear.

The Tribunal's reading of "credit rating" as being broadly defined creates uncertainty as to what is to be regarded as a credit rating and, therefore, when an information provider might be regarded as issuing a credit rating and so engaging in Type 10 regulated activity. Contra the analysis presented in this paper, information could possibly be regarded as a credit rating notwithstanding that creditworthiness is not its primary concern, it lacks ordinality, and the ranking system could not sensibly be used to rank creditworthiness. In addition, a variety of unspecified surrounding or extrinsic circumstances could also become relevant. Taken together, this represents a significant blurring of the clear perimeter sought by the SFO, regulators and market participants between different types of regulated and unregulated activities. The concerns of the SFC expressed during the consultations leading to the statutory CRA regime to "effectively distinguish between Type 4 and Type 10 regulated activities"195 is, per Chief Justice Li, relevant to consider to identify the purpose of the legislation. ${ }^{196}$ The Tribunal's determination, however, gives rise to some uncertainties as to what counts as research product and what counts as the special category of credit rating, and whether some persons licensed for Type 4 regulated activity might additionally need to be licensed for Type 10. This might lead to certain types of reports not previously regarded as credit ratings requiring reexamination. Existing regulated intermediaries will need to review their compliance procedures as to the management of information noting that disclaimers accompanying the information might not be of assistance. It may also make the Hong Kong market less attractive to potential information-providing market participants, including those looking to base new operations in Asia.

Second, the implications for a CRA holding or considering obtaining a Type 10 license in Hong Kong appear to change.

In consequence of the first point above, licensed CRAs and those CRAs considering obtaining a license in Hong Kong, would need to revisit the question of which of their activities are to be regarded as subject to the regulatory oversight of the SFC. The Moody's case suggests the Type 10 license could in effect become a proxy for the SFC to regulate a wider range of activities undertaken by CRAs than currently understood. To the extent the scope of a more inclusive oversight is uncertain, regulatory clarity is warranted. A broadening of regulatory oversight would also introduce new compliance burdens

\footnotetext{
195 SFC's "Consultation Conclusions Concerning the Regulatory Oversight of Credit Rating Agencies", 29 October 2010, para 22

196 At para 14 of Cheung Kwun Yin op. cit.: "Where the legislation in question implements the recommendations of a report, such as a Law Reform Commission report, the report may be referred to in order to identify the purpose of the legislation."
} 
for CRAs. To the extent these developments may be out of step with the approach taken internationally (see Section 6.1.2) Hong Kong may become a less competitive market for CRAs to base themselves.

Third, the disciplinary provisions of the SFO appear to be widened in an uncertain and uneven manner.

The concerns noted in the second point above are magnified when one considers, as noted in Section 3.3 above, the uncertainty created by the Tribunal's interpretation of "relating to the carrying on of any regulated activity"197 in the disciplinary provisions of the SFO. This is a concern not only for CRAs but also for all regulated intermediaries, namely, as to when a non-regulated activity is to be regarded as "relating to" one of their regulated activities and when it is not. Interpreting the phrase the way the Tribunal has done in effect extends the SFC's disciplinary powers to acts undertaken by regulated intermediaries even though such acts are not themselves regulated activities. This arguably extends the perimeter of regulatory oversight of the SFC in a way not intended by the Legislature. Since unregulated persons undertaking exactly the same acts need not be concerned, it is contended that an uneven playing field is created.

Fourth, as a result of the foregoing, is the potential consequence of the widening of a CRA's liability.

While the credit rating industry and the more recent developments in subjecting CRAs to regulatory oversight operate to reduce information asymmetries in the market ${ }^{198}$ the Tribunal's determination could be counterproductive. Some market commentators in Hong Kong have already noted that the Tribunal's determination may have far reaching effects on the freedom of information, particularly negative criticism, in the market. This may work to constrain the business and information-providing activities of not only CRAs but also others who provide advice and issue research. This could result in a reduction of the range of views being expressed in the market on matters such as quality of financial reporting, a company's business strategy, or its corporate governance standards. Over a decade ago Moody's submitted to the U.S. Securities and Exchange Commission that increasing legal liability "would also have the ultimate chilling effect on our ability to publish independent and potentially controversial opinions." 199 The Tribunal's determination effectively widens that concern to other information providers in the market.

\subsubsection{International context}

As discussed in Section 1.2, an essential element in the design and implementation of Hong Kong's CRA regulatory regime was that ratings in Hong Kong should be serviceable in the EU. The EU has recognized Hong Kong's legal and supervisory framework as equivalent to the requirements of the EU subject to three conditions that are to be met on a continuing basis (the "EU equivalence decision"). The European Commission, informed by the European Securities and Markets Authority ("ESMA"), will "continue to monitor the evolution of the Hong Kong legal and supervisory framework for CRAs". ${ }^{200}$

\footnotetext{
197 Section 193(1)(d). Emphasis added

198 See generally DW Arner et al, "Regulating Credit Rating Agencies in Hong Kong: Lessons from the Global Financial Crisis" Banking \& Finance Law Review 25.3 (Jun 2010), 361-403

199 Moody's letter dated 28 July 2003 in response to the U.S. Securities and Exchange Commission's "File No. S7-12-03, Concept Release: Rating Agencies and the Use of Credit Ratings under the Federal Securities Laws", page 4 200 Official Journal of the European Union, vol 57, 3 May 2014, page 77
} 
The EU equivalence decision is premised on ESMA's technical advice that "the Hong Kong legal and supervisory framework in respect of CRAs is comparable to that laid down in Regulation (EC) No 1060/2009." 201 Article 3, 1(a) of that regulation defines credit rating as meaning

"an opinion regarding the creditworthiness of an entity, a debt or financial obligation, debt security, preferred share or other financial instrument, or of an issuer of such a debt or financial obligation, debt security, preferred share or other financial instrument, issued using an established and defined ranking system of rating categories".

While there are obvious differences in the precise language used in the EU and Hong Kong definitions, ESMA's advice regarded the two as comparable. That assessment was made at a time when no statutory body or Court of law (in Hong Kong or elsewhere) had been asked to determine or rule on the precise scope of the statutorily defined terms. If the effect of the Tribunal's determination, or a subsequent Court ruling, was to represent a significant departure from the understanding of ESMA or the European Commission, this may suggest that a generally consistent approach has not developed in Hong Kong and conceivably could require a reassessment of Hong Kong's continued equivalence.

Accordingly, it becomes necessary to ask the following question: has the understanding in Hong Kong of what constitutes a credit rating been widened ${ }^{202}$ in such a way that might cause information being regarded as a credit rating in Hong Kong that would not be regarded as such in the EU? If such an equivalencegap arises, a central purpose of Hong Kong's CRA regime is at risk of failure.

One might rephrase the problem more specifically: would the issue of the RF Report or the red flag framework would be regarded for the purposes of EU regulation as that of a credit rating agency issuing a credit rating? If the answer is no and a Hong Kong Court ruling nevertheless supports the broad interpretation of the Tribunal, this would appear to confirm a problematic equivalence-gap exists that the European Commission may be obliged to consider.

The increased uncertainty of the CRA regime as suggested in Section 6.1.1 and the foregoing equivalence concern together appears to be at odds with Hong Kong's status as a leading international financial centre. ${ }^{203}$

To the extent such a conflict between regimes exists, Hong Kong regulators and policymakers should note that the concluding section to IOSCO's Final Report on "Regulatory Implementation of the Statement of Principles Regarding the Activities of Credit Rating Agencies" requires that they "should seek timely and reasonable accommodations so long as the IOSCO principles are not compromised." 204

\footnotetext{
201 Official Journal of the European Union, vol 57, 3 May 2014, page 76

202 I.e., along the lines of the term being "broadly defined" (Determination para 81 ) as the Tribunal would have it

${ }^{203}$ It is at odds with the role of the Hong Kong government under Article 109 of the Basic Law to maintain, and the duties of the SFC under section 6(2)(a) of the SFO to have regard to, Hong Kong's status as an international financial centre, and with the duties of the SFC

${ }^{204}$ Final Report FR04/11, February 2011, at page 38
} 


\subsection{Other provisions of the SFO are relevant}

Whatever the credit rating status of the RF Report, it remains a piece of information that has been distributed into the market and, fundamentally, the SFC's case against Moody's is based on the report being "unfair, unclear and misleading". ${ }^{205}$ The Tribunal also found that the RF Report was misleading ${ }^{206}$ (although this aspect has not been a focus of this paper ${ }^{207}$ ).

If one considers whether the legislative intent of protecting market integrity from misinformation (and unregulated participants ${ }^{208}$ ) is met by the SFO, it is not necessary to look to the CRA regime - other provisions of the SFO specifically deal with that. The Tribunal is of course limited to the matters relevant to the SFC's findings and is not able to consider those other provisions directly. ${ }^{209}$ However, it is within its remit to consider them in the context of statutory interpretation.

The following brief discussion illustrates the SFO does not lack other mechanisms that provide effective sanctions and remedies in relation to the SFC's base case against Moody's. As such, a broadening of the scope of the CRA regime is questionable insofar as it seems unnecessary to meet the overall objectives of the legislation.

The SFO provides for criminal ${ }^{210}$, administrative ${ }^{211}$ and civil $^{212}$ sanctions in respect of the negligent ${ }^{213}$, reckless or intentional dissemination of false or misleading information likely to induce transactions. ${ }^{214}$ These provisions in general apply to all providers of information, ${ }^{215}$ whether or not regulated by the SFC. CRAs have no particular immunity from such provisions and Moody's may be exposed to

205 SFC enforcement news, 5 April 2016. In the SFC's Notice of Proposed Disciplinary Action, it "informed Moody's that it was of the preliminary view that the Report (and its related press release) contained misleading, inaccurate and unfair statements." As cited by the Tribunal in Determination para 45

206 Determination para 177

207 Aspects of the Tribunal's understanding of the non-correlation aspects of the report have been questioned in Section 4 and suggest a re-reading of the report is required that is independent of Moody's status as a CRA.

${ }^{208}$ As regards regulated activities, if the RF Report is not a credit rating does it mean Moody's has engaged in some other regulated activity, such as Type 4 (advising on securities), when it distributed the report (or other reports like it)? This would require a different analysis from the one undertaken in this paper, namely, whether the statutory definition briefly discussed in Section 3.2.1 is satisfied. If it was, then Moody's would be conducting regulated activity without a license which is a criminal offence under section $114(1)(a)$ of the SFO. However, this seems unlikely having regard to the nature of the RF Report, the special role of CRAs and their business analyses, and the wider consequences of any such finding.

209 Determination para 121

210 Section 298 of the SFO, which requires mens rea, provides for penalties of up to 10 years imprisonment and/or a HK\$10 million fine

${ }^{211}$ Section 277 of the SFO provides for sanctions able to be imposed by the Market Misconduct Tribunal that include director disqualification, disgorgement of profits, and costs orders

212 Section 391 of the SFO provides for damages in respect of the pecuniary loss of investors acting or refraining to act in reliance on the information

213 Save that section 298 is not relevant where the act was merely negligent

214 Sections 277, 298 and 391 of the SFO

215 Subject to carve-outs for persons who reproduce, re-transmit or broadcast the information in the ordinary course of their business 
potential liability under these sections of the SFO, irrespective of whether the RF Report is regarded as comprising a credit rating or the Court of Appeal's ruling. ${ }^{216}$

The Tribunal does take issue with facts presented in the RF Report that appear to be in error and that are admitted by Moody's although they have contended the errors are not material. ${ }^{217}$ That the RF Report was likely to induce transactions seems confirmed, at least when considered in the rearview mirror.

The SFO also provides for remedies. Section 213 of the SFO can be invoked by the SFC where there has been, inter alia, a contravention of the SFO or any of the terms and conditions of any licence or registration under the SFO. It has been used by the SFC to obtain ${ }^{218}$ from the Court an order "to restore the parties to any transaction to the position in which they were before the transaction was entered into". ${ }^{219}$ Given the substantial share price falls incurred, allegedly as a consequence of the report, in both the share and bond markets in respect of a number of companies the subject of the report, any restoration order would dwarf the HK\$11 million regulatory fine currently imposed on Moody's. However, there would be practical difficulties to apply section 213 in the Moody's case. ${ }^{220}$

${ }^{216}$ As the present case concerns a regulatory sanction of an administrative nature, there is nothing in principle that would prevent the SFC, or a private investor, from also bringing an action under the misinformation provisions

217 Determination para 56. One commentator has suggested that the Moody's report was only very marginally in error, suggesting it is only $1.2 \%$ wrong stating that only 12 flags were wrong out of 980 allocated. However, that is the wrong perspective - the correct approach requires a materiality assessment on a company-by-company basis

218 The landmark case being SFC v Tiger Asia and Others [2013] HKCFA.

219 Section 213(2)(b) of the SFO

220 The Court would need to consider it desirable to make an order (Section 213(4) of the SFO). While determining the extent of restoration is always complicated in practice, the fact that the negative outliers identified by Moody's have in fact performed poorly over a 5 year period raises questions over what time horizon should be employed to measure loss ("4 of the 6 'negative outliers' defaulting on their debts within 4 years, and the other 2 having massively under-performed the stock market" - quoted from https://webbsite.com/articles/moody.asp). To date, the Courts have applied section 213(2)(b) only to persons who have actually transacted with the wrongdoer as counterparty (i.e., before novation of the matched trade to the HKEx's central counterparty), consistent with the general concept of unfair bargaining position. However, the language of the section is not specifically restricted in this manner and it remains open to the Court to apply the section to the benefit of other persons. (Requiring the counterparty element ignores the reality of anonymous trading and the randomised matching of orders undertaken by the stock exchange's automated matching system, effectively making it a lucky draw as to which persons obtain the benefit of a restoration order against a wrongdoer. See $S$ Johnstone, "A flawed debate" International Financial Law Review, May 2015, 38-39, p.38). In September 2014 the SFC commenced proceedings in the Court of First Instance (Against CITIC Limited (CITIC) and five of its former executive directors. See https://www.sfc.hk/edistributionWeb/gateway/EN/news-andannouncements/news/doc?refNo=14PR108 (last accessed June 2016)) that may see a development in this regard - the SFC appears to be seeking restoration orders for persons who have merely traded during a specified period without appearing to require any counterparty requirement. While the Courts in Hong Kong have not as yet embraced an approach similar to the fraud on the market theory that has been adopted in the U.S. (For example: Peil v. Speiser 806 F.2d 1154, 1160-1161 (CA3 1986); Basic v Levinson U.S. Supreme Court 1988; Halliburton v Eric P John Fund U.S. Supreme Court 2014), this may soon change. If it does, this may have implications for other providers of information to the market, including Moody's. 


\section{CONCLUSIONS ON CREDIT RATING}

Based on the effects of the RF Report in the market, the report appeared to be of considerable interest to both equity and debt investors. The environment of concern of regulators and investors over governance and accounting standards in Mainland companies, the targeted nature of the RF Report, the cautionary note of its red flags, and Moody's status in the market, together contributed to this.

Section 4 - an analysis of the statutory meaning of "credit rating" - represents one starting point for assessing whether the issuance of the RF Report constituted the provision of a credit rating. A close review of the statutory language suggests that it is not because the basic requirements of the statutory definition are not satisfied. (1) While the RF Report does discuss matters pertaining to credit risk it does not appear to be primarily concerned with creditworthiness (as such term is properly understood). ${ }^{221}$ (2) The red flag framework can be regarded as a defined ranking system but it lacks both the ordinality normally required of credit ratings and the ability to be used to meaningfully signify creditworthiness. (3) The language of the RF Report on a plain reading appears to eschew a connection between the red flag framework and creditworthiness. (4) The factors examined by the report may share commonalities with factors relevant to methodologies used by CRAs but no opinion on creditworthiness appears to have been expressed. Taken together, the foregoing does not point to a credit rating that is a defective one - it points to a report that is not a credit rating.

Section 3 addressed another possible starting point for the assessment - the one taken by the Tribunal - looking outside the four sides of the RF Report as part of a purposive interpretation to give effect to the legislation. That approach takes as its focus the regulated activity of providing credit rating services. As regards the consideration of extrinsic matters, the CRA regulatory regime makes no provision to consider such matters. This notably stands in contrast to other provisions of the legislation that seek to attain similar objectives such as the quality of information in a market place and a clear delineation of regulated and unregulated activities. This suggests the Legislature did not intend extrinsic factors to be taken into account when determining the scope of the CRA regulatory regime. Section 5 above nevertheless considered the import of the press release. It was suggested that the press release does not materially alter the nature of the RF Report, in particular, that the single use of one phrase, "supplemental to", is insufficient to do so.

Section 6 considered the relationship between the Tribunal's determination and the furthering of legislative intent. As noted in Section 1.3, although the Tribunal's determination is technically incapable of affecting the law it is nevertheless highly influential as to how the SFC goes about executing its regulatory function as well as the undertakings of regulated persons. However, when the Court of Appeal rules on Moody's appeal, law is established. It suggested that, should the Court of Appeal uphold the Tribunal's approach, there may be consequences both domestically and internationally at odds with the policies and intent of the Legislature.

Any analysis of information connected to the CRA industry must be astute to important differences between elements of credit risk, the methodology that is applied to a task, the concept of creditworthiness, and the opinion that might be expressed on creditworthiness. These distinctions underlie the fact that not all information issued by CRAs constitute credit ratings. Conflating them leads to a

${ }^{221}$ See Section 4.2 above 
muddled understanding of a CRA's undertaking, a confused approach to the statutorily defined term "credit rating", and consequential errors of analysis.

It must also be informed by the overarching regulatory objectives of introducing CRA regulation. Locally, this includes ensuring ratings issued in Hong Kong meet international standards and are serviceable in the EU. A primary aim of regulating CRAs is to foster the reduction of information asymmetry among market participants. Potential developments that may tend to restrict a CRA's function in that regard should be examined closely in view of that objective.

Given that (1) the definitions of "credit rating" and Type 10 regulated activity are clearly expressed and as such appear to serve their regulatory purposes, (2) other provisions of the SFO adequately address the problem of misleading information entering the market, and (3) the potential problems attendant on the Tribunal's approach, there does not appear to be any good reason to broaden their scope in the way undertaken by the Tribunal.

Accordingly, the conclusion reached in this paper is that the issue of the RF Report and the red flag framework in it should not be regarded as constituting Type 10 regulated activity or a credit rating as such terms are defined by the law.

\section{THE REGULATORY APPROACH}

Setting aside the analysis and conclusions of this paper, it is worth considering some broader perspectives on the Moody's case.

When the new CRA regime was introduced CRAs were, in effect, to undertake the same activities as they had long been doing albeit under the new context of a regulatory environment in which their credit rating activities were to be overseen by a new regulator. At the time Moody's issued the RF Report the CRA regulatory regime was only 41 days old. Of course, CRAs such as Moody's were already well aware of the international developments since 2003 and had ample time and involvement in the development of the regulations in Hong Kong to be aware of their scope and requirements. Nevertheless, as discussed in Section 2.3 above, at that time there remained some lack of clarity in the market on how certain aspects of the SFC General Code would apply to CRAs. Teething troubles are not unusual in the introduction of any significant change in law or regulation. It seems not unreasonable to state that both regulator and regulatee were in the process of establishing and understanding the new relationship and how the details of the new regime would operate in practice.

The SFC's approach to the RF Report, electing to pursue Moody's publicly under the CRA regime, is in some ways puzzling when one considers (1) the newness of the CRA regime, (2) that it required treating the issuance of the RF Report as being clearly a part of Moody's Type 10 regulated activities and not merely a research report falling under a CRA's other business analysis activities, (3) that no breaches of the more targeted SFC CRA Code were alleged and (4) the alternative approaches available to the SFC (assuming for this purpose the SFC's perception of the RF Report).

The matter could have been handled on a private reprimand basis. However, perhaps the SFC was of the view that such a sanction would have been inadequate. The SFC did consider the report to be misleading and, as understood through the lens of the Tribunal's determination, appeared to consider it the cause of transactions having effects in the share and debt markets. One route therefore would have been to bring an action under the information based provisions of the SFO discussed in Section 6.2 above. As already noted, that 
route remains open to the SFC irrespective of any regulatory sanction it applies under its disciplinary powers. One might ask whether, in the larger scheme of things, the RF Report was sufficiently egregious to warrant actions under those provisions. If it was, then why has action not yet been taken five years after the report was issued?

Perhaps the RF Report did not clearly warrant that kind of action because it was not sufficiently offensive to market integrity or prejudicial to the interest of the investing public or public interest. Pursuing Moody's through the Courts under the SFO provisions is also far more time consuming, expensive and ultimately uncertain as to its outcome. The SFC is under a statutory obligation to consider the efficient use of its resources. ${ }^{222}$ Given these considerations, an alternative is to approach the matter as a breach of regulatory codes. One might also note the potential effect a public sanction and fine could have on a newly regulated segment of the market, possibly reinforcing the message that CRAs were now subject to the SFC's oversight - and disciplinary powers - and accordingly that CRAs would need to ensure they comply with the standards set out in the applicable SFC codes of conduct. This might also serve to foster the objectives of the CRA regime and promote market integrity at a time when the global financial crisis and the role of rating agencies was still very much a recent and highly sensitive issue. Regulators abroad, notably in the U.S., had also been subject to considerable criticisms for certain oversight failures in relation to the crisis. A decision to impose regulatory discipline might therefore serve a number of purposes. However, while the SFC's disciplinary sanctions are rarely appealed to the Tribunal, and have never before been appealed beyond the Tribunal, they can be, as Moody's have done.

Effective regulation frequently comprises an element of seeking the right balance and making assessments as to the gravity of a perceived wrongdoing, and it is not the purpose of this paper to second-guess decisions made by the SFC that may rest on strategic, policy or other considerations. The RF Report is not free from errors and uncertainties. Nevertheless, with an eye on accepted regulatory values such as transparency and accountability (and putting aside the analysis presented in this paper), one can ask whether there was an alternative case for a more nuanced approach to a perceived shortfall in standards, managing the introduction of a new regulatory regime and effectively bringing an existing and well established industry within the SFC's oversight. Law alone does not establish an effective regulator-regulatee relationship.

In short, was pursuing Moody's in the way the SFC did the best way of sanctioning Moody's and/or promoting compliance amongst the CRA community? Is engaging a new group of licensees in common regulatory objectives, such as market integrity, more or less likely to be fostered through litigation, stronger discipline, or through other means? Certainly, it is widely understood that the prospect or fear of litigation or disciplinary disputes with a regulator rightly or wrongly often tends to restrict channels of communication rather than to facilitate them. To that extent, strategic partnerships between regulator and regulatee that work to foster market standards may be less likely to form.

${ }^{222}$ Section $6(2)(e)$ of the SFO 